\title{
Thermal Conductivity Standard Reference Materials From 4 to 300 K. I. Armco Iron: Including Apparatus Description and Error Analysis*
}

\author{
J. G. Hust, ${ }^{* *}$ Robert L. Powell, ${ }^{* *}$ and D. H. Weitzel ${ }^{* *}$ \\ Institute for Basic Standards, National Bureau of Standards, Boulder, Colorado 80302
}

(May 15, 1970)

An apparatus for the measurement of thermal conductivity, electrical resistivity, and thermopower of solids from 4 to $300 \mathrm{~K}$ is described. This apparatus, a modified version of the one used earlier in this laboratory, utilizes the steady-state, axial heat flow method. Included is a detailed discussion of the limitations of the apparatus, probable errors, and data analysis methods.

Thermal conductivity, electrical resistivity, Lorenz ratio, and thermopower data are reported for several specimens of Armco iron for temperatures from 4 to $300 \mathrm{~K}$. At low temperatures the electrical resistivity and thermal conductivity vary from specimen to specimen by more than 10 percent. However, the Lorenz ratios of these specimens differ by less than 2.5 percent; and the intrinsic resistivities calculated by using Matthiessen's rule differ by less than 0.5 percent of the total resistivities. Thus, Armco iron specimens can be used as standards by measuring the residual resistivities and utilizing the Lorenz ratio reported here.

Key words: Cryogenics; equipment; electrical resistivity; error analysis; iron; Lorenz ratio; Seebeck effect; thermal conductivity; transport properties.

\section{Contents}

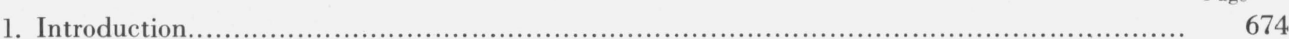

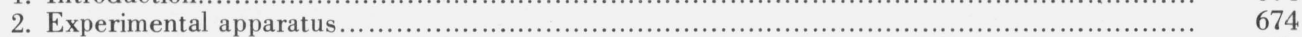

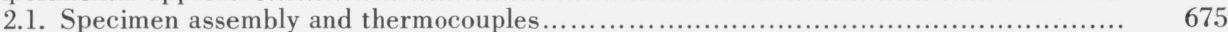

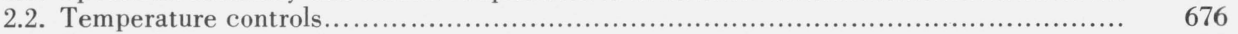

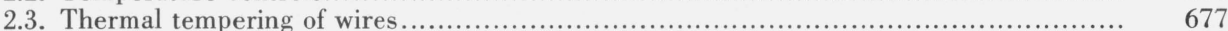

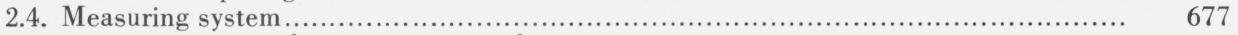

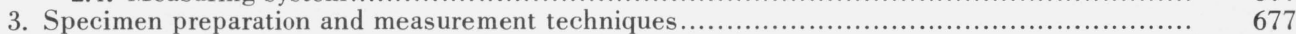

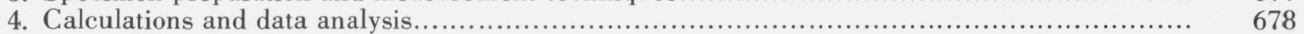

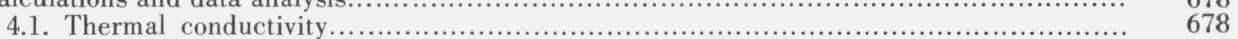

4.1.1. Difference method............................................................. 678

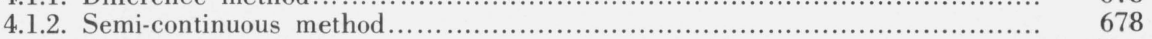

4.1.3. Continuous method ......................................................... 678

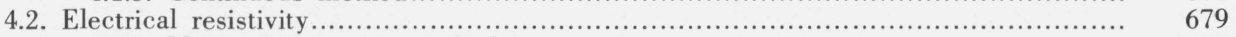

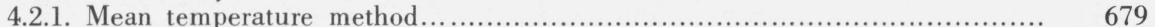

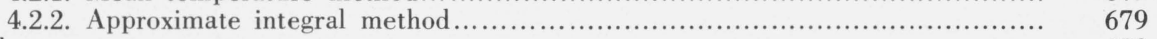

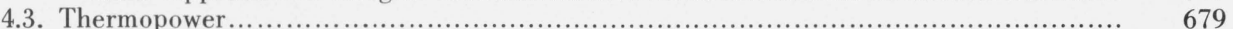

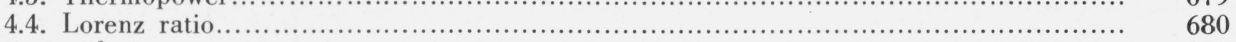

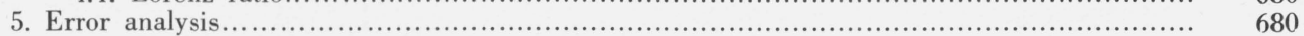

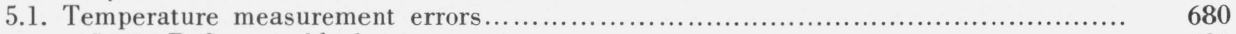

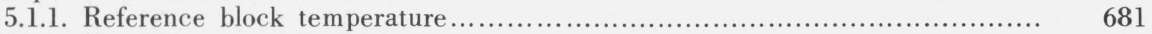

5.1.2. Specimen temperatures...................................................... $\quad 681$

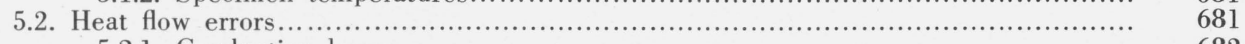

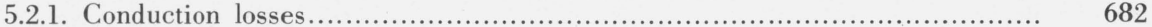

5.2 .2 . Radiation losses.......................................................... 682

5.2.3. Temperature drift effects.................................................. 682

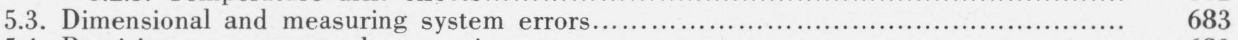

5.4. Precision, accuracy, and uncertainty................................................ 683

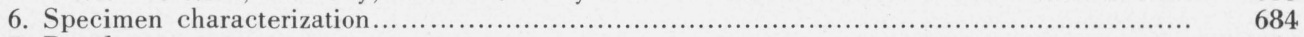

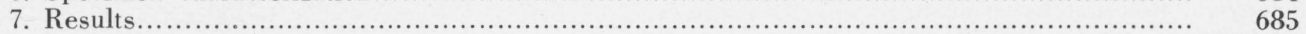

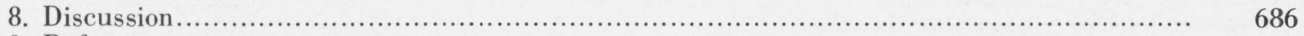

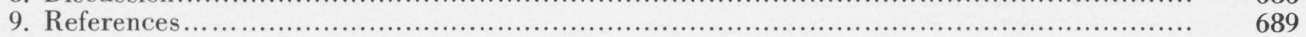

*This work was carried out at the National Bureau of Standards under the sponsorship of the NASA(SNPO-C), Contract K-45.

${ }^{* *}$ Cryogenics Division, National Bureau of Standards, Boulder, Colo. 80302. 


\section{Introduction}

The development of new structural materials and renewed interest in existing materials by the aerospace industry is creating a demand for thermal and electrical property measurements on these materials. Such data are needed for the selection of suitable construction materials and the prediction of operating characteristics of low-temperature systems. To help satisfy the immediate needs for these data, an apparatus has been built to measure the thermal conductivity, electrical resistivity, and thermopower of solids. This apparatus is designed to measure samples with thermal conductivities varying from 0.1 to $5,000 \mathrm{~W} / \mathrm{mK}$ at temperatures from 4 to $300 \mathrm{~K}$.

Thermal conductivitity data of technically important solids accurate to 5 percent satisfy current demands. However, future demands will likely be more stringent. For this reason the present program is directed toward the acquisition of thermal conductivity data which are accurate to within 1 percent. Thermal conductivity data accurate to within 1 percent are difficult to determine, especially for poor conductors or at temperatures above about $120 \mathrm{~K}$, because of the difficulty of maintaining thermal losses at a sufficiently low level.

Measurements have been made on several aerospace alloys, Hust et al. [1]. ${ }^{1}$ Another phase of this program, to establish standard reference data on several reference materials (or specimens), has begun. We intend to measure several specimens of materials which appear to be useful as standards. For some materials, material variability may be so great that only standard reference specimens, i.e., measured specimens (not standard materials), will be useful. Standard reference specimens or materials are useful for intercomparison of existing apparatus, for debugging new apparatus, and for calibration of comparative apparatus. The apparent large differences between the results of various investigators for a given material $(50 \%$ is not unheard of) are evidence of the need for intercomparisons, calibrations, and standardization. The availability of standard reference materials will result in more accurate and more permanent transport property data for technically important solids.

This paper contains the results of our measurements on the transport properties of Armco iron. ${ }^{2}$ Armco iron was investigated at low temperatures primarily because of its extensive use as a thermal conductivity standard at higher temperatures by R. W. Powell ${ }^{3}$ and others [2]. Also included are a complete description of the apparatus, data analysis methods, and uncertainty analysis of the results. This apparatus is similar to that described by R. L. Powell et al. [3]; however, a sufficient number of modifications have been made to warrant a complete new description.

\footnotetext{
${ }^{1}$ Figures in brackets indicate the literature references at the end of this paper.
${ }_{2}^{2}$ The use in this paper of trade names of specific products is essential to a proper understanding of the work presented. Their use in no way implies any approval, endorsement, or recommendation by the National Bureau of Standards. Armco iron is a registered trade name of a commercially pure iron produced by Armco Steel Corporation.

${ }^{3}$ Two authors in this field have the same surname. R. W. Powell has done most of his research above room temperature. For many years he was at the National Physical Laboratory in England; he is now at the Thermophysical Properties Research Center of Purdue University.
}

\section{Experimental Apparatus}

Of the many methods described in the literature for the measurement of thermal conductivity, probably the simplest both conceptually and mechanically is the axial heat flow method. In this configuration the specimen is in the form of a rod with constant crosssectional area and the heat flow is along the axis of the rod. This configuration is also convenient for the simultaneous measurement of the electrical resistance and the Seebeck voltage. Accurate measurements can be obtained by this method as long as radiation and other radial losses can be limited to a reasonable value. Above $300 \mathrm{~K}$ this is difficult to do except for good conductors. The temperature range of interest in this work is below $300 \mathrm{~K}$; thus the axial heat flow method was chosen to obtain the most accurate data. The apparatus is shown in figure 1 .

The cryostat consists of concentrically mounted specimen, specimen shield (filled with glass fiber), vacuum can, and glass cryogen dewar. The glass dewar is supported by a stainless steel container soldered to the top plate to create a closed system. This system is immersed in a nitrogen-filled stainless steel dewar. For temperatures up to about $200 \mathrm{~K}$, the inner glass dewar

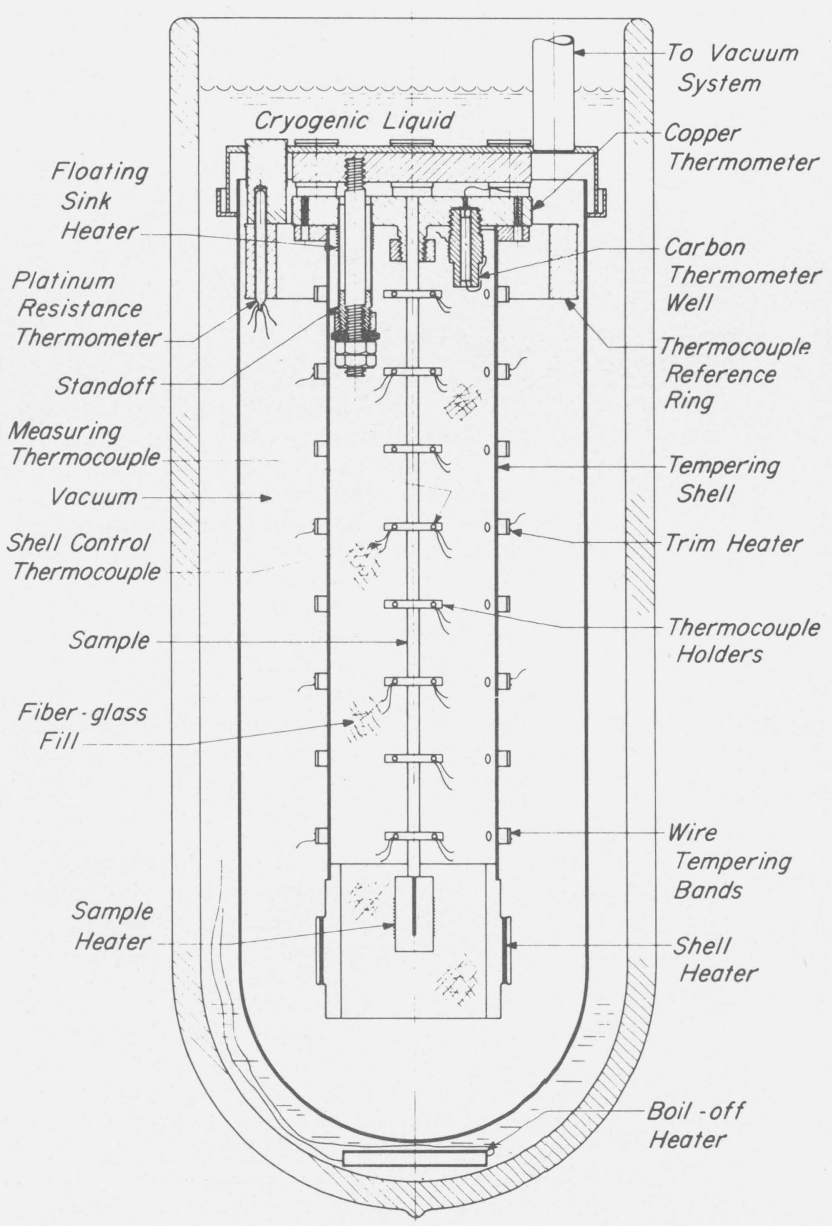

FIGURE 1. Thermal conductivity apparatus. 
is filled with liquid helium, hydrogen, or nitrogen depending on the temperature range desired. The outer dewar is filled with liquid nitrogen to reduce the boil-off rate of the liquid in the inner dewar. The pressure above the liquid in the inner dewar is controlled with a manostat to isolate the bath from atmospheric pressure variations which in turn would create temperature variations of the bath. To obtain measurements in the range of 200 to $300 \mathrm{~K}$, the outer stainless steel dewar is removed and the inner dewar is filled with either a dry ice-alcohol bath or an ice-water bath.

The top end of the specimen is clamped to a temperature-controlled copper heat sink (floating sink). A heater is attached to the bottom end of the specimen. The temperature of the specimen is determined at eight equally spaced positions along its length by thermocouples fastened to knife-edged thermocouple holders. Heat losses from the specimen are minimized by evacuating the specimen chamber, surrounding the specimen with a temperaturecontrolled cylindrical shell, and filling the space between the specimen and shell with glass fiber. The upper end of the shell surrounding the specimen is attached to the floating sink. The shell temperature distribution is controlled by means of a main heater at the bottom of the shell and three trim heaters equally spaced along the shell. The temperature differences between the specimen and shell are determined by differential thermocouples located at the heater positions.

The floating sink is attached to the lid of the vacuum can by means of three replaceable standoff bolts and sleeves. An electrical heater is wrapped on the sleeves to allow temperature control of the floating sink and thus the upper end of the specimen and surrounding shield.

A heavy copper ring (about $10 \mathrm{~cm}$ diam, $1 \mathrm{~cm}$ thick, and $2.5 \mathrm{~cm}$ long) is attached to and in good thermal contact with the lid of the vacuum chamber. This lid in turn is in direct contact with the pressure-controlled cryogenic liquid. The copper ring serves as the temperature reference for all of the thermocouples in the system. Mounted in the copper ring is a platinum resistance thermometer to determine the reference temperature for temperatures above $20 \mathrm{~K}$. The reference temperature at helium temperatures is determined by the vapor pressure of the liquid helium.

The electrical resistance of the specimen is determined by passing an electrical current through it and measuring the potential drop between thermocouple holders number one and eight. Forward and reverse readings are taken to eliminate the Seebeck voltage from this measurement. The Seebeck voltage (thermovoltage) is determined from the difference in forward and reverse readings and is also measured directly with zero electrical current. These determinations of the Seebeck voltage agree with one another to within the noise of the null detector system $( \pm 0.01 \mu \mathrm{V})$. The Seebeck voltage is measured with respect to "normal" $\mathrm{Ag}$ wire $(\mathrm{Ag}-0.37$ at \% $\mathrm{Au})$.

The differences between this apparatus and that described earlier by R. L. Powell et al. [3] are (1) the addition of the floating sink and its associated control circuitry, (2) two additional trim heaters along the shell surrounding the specimen, (3) use of glass fiber radiation shielding around the specimen necessary for extending measurements above $120 \mathrm{~K}$, (4) pressure control on the space above the cryogenic liquid, (5) use of thermocouples with a higher sensitivity and stability at low temperatures, and (6) use of more advanced electronic control circuitry and measuring apparatus.

\subsection{Specimen Assembly and Thermocouples}

The specimen is clamped at its upper and lower ends to the floating sink and specimen heater, respectively. To improve the thermal contact at these clamps, a low vapor pressure thermal contact grease is applied. Better contact has been obtained using an alloy of indium and gallium (liquid at room temperature). However, it was found that this material reacts with aluminum, for example, and probably diffuses quite rapidly with other samples. Its use was discontinued until more of its characteristics are understood.

The specimens are $23-\mathrm{cm}-$ long cylinders. The crosssectional area of each is based on the thermal conductivity of that specimen. The best conductors have the smallest cross-sectional area $\left(0.1 \mathrm{~cm}^{2}\right)$, while the poorest conductors have the largest cross-sectional area $\left(1 \mathrm{~cm}^{2}\right)$. The diameter of each specimen is measured to within $\pm 0.0001 \mathrm{~cm}$ at several points along its length. The maximum diameter variation of each specimen is about $\pm 0.0003 \mathrm{~cm}$ from the mean diameter.

The thermocouples are attached to the thermocouple holders via epoxy cement, a metal cylinder, and a coating of low vapor pressure thermal contact grease. This assembly is shown in figure 2 . The knife edge on each thermocouple holder fits into a machined groove $(0.05 \mathrm{~mm}$ deep) on the specimen. These grooves are machined at a spacing of $2.540 \pm 0.003 \mathrm{~cm}$. The actual spacing is determined with a goniometric microscope to $\pm 0.0001 \mathrm{~cm}$.

The temperature measuring and differential thermocouples are ISA Type KP versus $\mathrm{Au}-\mathrm{Fe}(\mathrm{Au}-0.07$ at $\% \mathrm{Fe}$ ). These thermocouples were fabricated from single rolls of type KP and Au-Fe wires. Segments

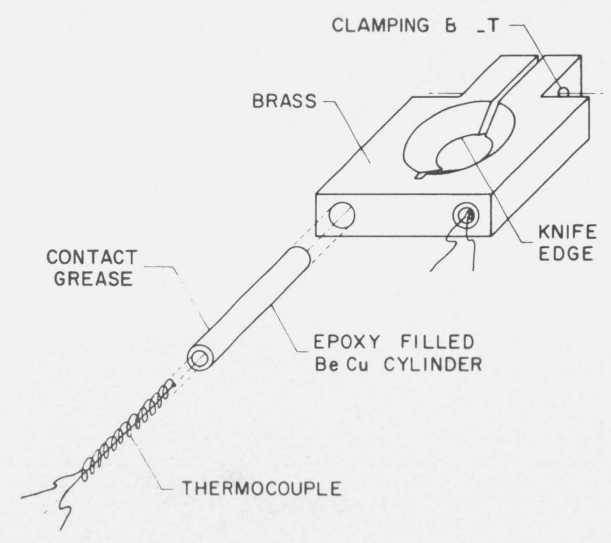

FigURE 2. Thermocouple mount. 
of wire from the beginning and end of these rolls were spot calibrated in the range 4 to $300 \mathrm{~K}$ using the boiling points of liquid helium, liquid hydrogen, and liquid nitrogen, the sublimation point of $\mathrm{CO}_{2}$, and the triple point of water. These spot calibrations were compared with the standard table (as established at this laboratory by Sparks et al. [4], and a new table was established for these thermocouples. The differences between thermocouples from the same roll were negligible, i.e., the emf of a thermocouple constructed from the opposite ends of the $\mathrm{Au}-\mathrm{Fe}$ wire used in this apparatus was less than $1 \mu \mathrm{V}$ with one junction in liquid helium and the other junction in ice. This represents a change in the mean thermopower of less than 1 part in 5000. One of the thermocouples in the apparatus was also intercompared with a germaniumresistance-thermometer from 4 to $30 \mathrm{~K}$. In this range no difference could be measured, to within $1 \mu \mathrm{V}$, between this thermocouple and those fabricated for spot calibration. The thermopower of the standard thermocouple is illustrated in figure 3 . The emf differences between the thermocouples used in this apparatus and the standard calibration table are shown in figure 4.

The standard table for these thermocouples presented by Sparks et al. [4] is based on the temperature scale IPTS-68 above $20 \mathrm{~K}$ and on the NBS P2-20 (1965) scale below $20 \mathrm{~K}$. The IPTS-68 is the present best estimate of the thermodynamic temperature scale. The gradient along the specimen as determined from these thermocouples and used for calculating thermal conductivity is thus based on these scales.

\subsection{Temperature Controls}

High-precision temperature controllers are used on the floating sink, the shell surrounding the specimen, and the cryogenic liquid surrounding the specimen chamber. The first two are electronic while the latter

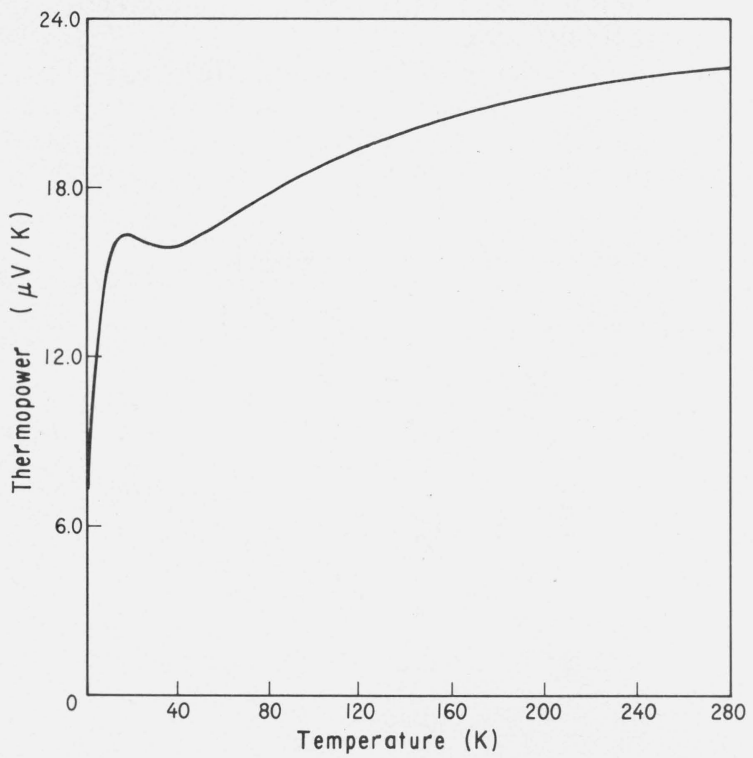

Figure 3. Thermopower of chromel versus Au-Fe (Au-0.7 at \% Fe).

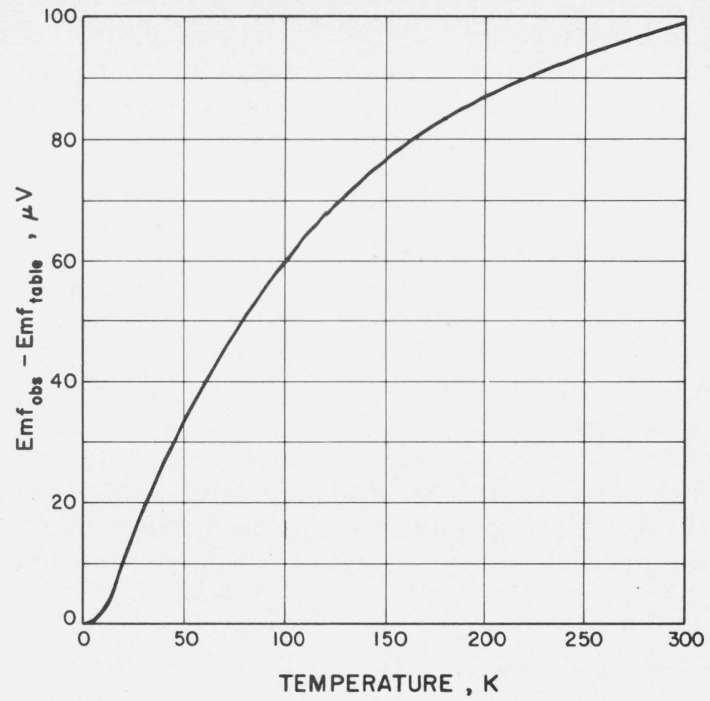

FigURE 4. Emf differences between the thermocouples used in this apparatus and the standard calibration table.

is mechanical. The heart of the electronic controllers is a de proportional and integral amplifier capable of $1 \mathrm{mK}$ control when used in conjunction with a dc bridge, differential thermocouples, and conventional low-level (microvolt) amplifiers. This unit was developed by J. C. Jellison and N. C. Winchester of the NBS Cryogenics Division. The control circuit for the floating sink is shown in figure 5. The sensing resistor is a copper wire resistor for temperatures above about $30 \mathrm{~K}$ and a conventional carbon resistor for temperatures below about $30 \mathrm{~K}$. The dummy leads shown are leads from the instrumentation rack to the cryostat paralleling those to the sensing resistor. This is to compensate for temperature drift effects on the sensing resistor leads. This circuit is capable of controlling the floating sink temperatures, and therefore

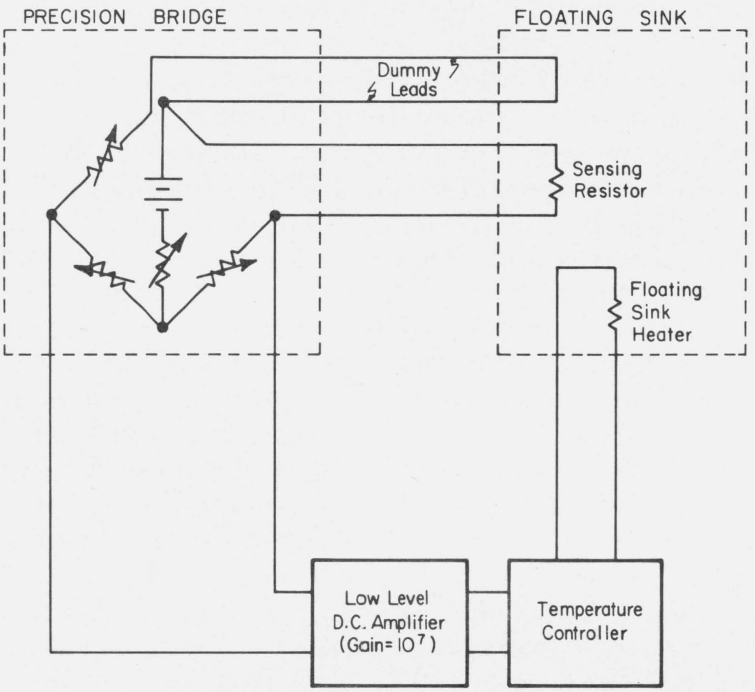

Figure 5. Control circuit for floating sink. 
the upper end of the specimen, to better than $1 \mathrm{mK}$.

The shell-to-specimen difference temperature is controlled with a similar circuit, but the sensing elements are the differential thermocouples between the shell and specimen. This circuit is capable of maintaining the shell temperature within $1 \mathrm{mK}$ of the specimen temperature at the control point. The bottom (main) heater and the three trim heaters on the shell are automatically controlled.

The mechanical pressure control (manostat) on the cryogenic liquid surrounding the cryostat is capable of controlling the vapor pressure of the liquid to about 0.1 torr. This manostat is similar to one described by Cataland et al. [5]. For liquid nitrogen, hydrogen, and helium at their normal boiling points this corresponds to temperature control of $1,0.3$, and $0.1 \mathrm{mK}$, respectively. At the triple point of nitrogen a pressure variation of 0.1 torr corresponds to a temperature variation of $5 \mathrm{mK}$. These numbers are somewhat unrealistic, since undoubtedly there is some stratification in the liquid. Thus, as the liquid level drops due to boil-off, the temperature at a fixed point in the dewar changes slightly even though the pressure at the surface remains constant.

\subsection{Thermal Tempering of Wires}

All of the leads attached to the specimen assembly are brought horizontally to the shell, then up the shell, and finally to the reference temperature block. On the reference temperature block the wires are all soldered to small copper wires which are taken out of the vacuum system via stainless steel tubes and wax seals at room temperature. It is important that the wires are brought into near thermal equilibrium with the shell and reference block respectively. To accomplish this, a calculated length of wire is cemented to an isothermal region of each of these components. The length calculation has been performed (with a safety factor of about 5) as described by Hust [6] to assure a temperature difference of less than $1 \mathrm{mK}$. Bringing about such equilibrium is here referred to as thermal tempering or just tempering.

It is obvious in the case of the reference temperature block that these wires must be tempered to the reference block. Any errors which are present due to poor thermal tempering will appear directly in the apparent temperature of the sample. The differential thermocouples used to control the sample-to-shell temperature differences must also be well tempered to the proper isothermal region on the shell. To create isothermal regions on the shell, copper bands are attached to the stainless steel shell at each measuring position. Again the length of wire required to temper to within $1 \mathrm{mK}$ has been used. All leads from the specimen are thermally tempered to the shell at the appropriate location to minimize the conduction heat loss along these leads.

All of the copper leads going from the reference temperature block to room temperature are thermally tempered to a copper block in contact with the liquid nitrogen in the outer dewar. This is to reduce heat flow to the reference block and also to reduce the boil-off rate during liquid helium tests.

\subsection{Measuring System}

To determine the thermal conductivity, electrical resistivity, and thermopower as a function of temperature we need to determine the temperature of the reference block, the temperature distribution of the specimen, the specimen heater power, the specimen resistance, the Seebeck emf, and the dimensions of the specimen. The emfs are measured with a sevendial potentiometer-null detector system. The temperature of the reference block is determined from the resistance of a platinum resistance thermometer (No. 1037903) calibrated from 10 to $90 \mathrm{~K}$ on the NBS-55 scale and above $90 \mathrm{~K}$ on the IPTS (1948) scale. Corrections as compiled by Hust [7] have been applied to convert both of these to the IPTS -68 . The $1958 \mathrm{He}^{4}$ vapor pressure scale [8] is used to establish the reference block temperature for the liquid helium tests.

The specimen heater power is determined by measuring the electrical current and voltage across the specimen heater. The voltage-measuring leads are connected so as to include one-half of the power generated in the current leads between the specimen and shell. This is based on the assumption that about one-half of the heat generated in these leads flows to the specimen heater while the other half flows to the shell. The electrical resistance of the wire from specimen-to-shell is about 0.2 percent of the total heater resistance. This connecting wire was selected as a compromise to satisfy two conflicting criteria: (a) small electrical resistance compared to the heater resistance, (b) large thermal resistance to minimize heat conduction from specimen-to-shell.

A strip chart recorder is part of the measuring system to facilitate observation of drift rates and other fluctuations in any of the measured voltages. This is used to indicate the degree of steady state achieved.

\section{Specimen Preparation and Measurement Techniques}

The specimens are machined and ground to specified nominal dimensions, after which they are accurately measured in a temperature-controlled measurement lab. Without further mechanical or thermal abuse, each specimen is fitted with thermocouple holders and heater. The specimen assembly is installed in the cryostat, the space between the shell and specimen is packed with glass fiber, and the vacuum can is soldered into place. The cryostat is evacuated to better than $10^{-5}$ torr and is subsequently cooled with the desired cryogenic liquid. The specimen is brought into equilibrium with the bath temperature (helium exchange gas at about 0.1 to 0.5 torr is generally introduced into the vacuum space to speed the approach to equilibrium). With all power to the specimen and shield heaters off, the zero emfs of the thermocouples are read. These zero corrections, caused by various inhomogeneities in the circuit, are considered to be constant throughout the run with each different cryogenic bath. 
Data on a given run are taken only after thermal steady state has been established with a vacuum of better than $10^{-5}$ torr. Thermal steady state is considered established after systematic drift of the indicated thermocouple temperatures are below the detectability or controlability limit, approximately $1 \mathrm{mK}$ per hour.

Isothermal resistivity data are obtained at the same time that the zero emfs are recorded. Also, to obtain further isothermal resistivity data and information regarding the differences between the eight measuring thermocouples, data are taken with the floating sink above the temperature of the surrounding bath but with no heat input to the specimen. The thermocouples thus indicate the temperature difference from the specimen to the reference block. If the specimen is at equilibrium with the floating sink, all eight thermocouples should produce the same emf. The scatter in these recorded emfs is an indication of the validity of using a single calibration table for all eight thermocouples. These measurements indicate that the thermocouple sensitivities are the same to within to 0.1 percent.

\section{Calculations and Data Analysis}

\subsection{Thermal Conductivity}

The defining equation for one-dimensional heat flow is

$$
\dot{Q}=-\lambda(T) A \frac{d T}{d X}
$$

where $\dot{Q}$ is the rate of heat flow through the rod, $\lambda(T)$ is the thermal conductivity of the rod at temperature $T, A$ is the cross-sectional area of the rod, and $d T / d X$ is the temperature gradient along the rod at temperature $T$.

Solving for $\lambda(T)$ we obtain

$$
\lambda(T)=-\frac{\dot{Q}}{A} \frac{d X}{d T} .
$$

Several methods can be used to obtain $\lambda$ values from the experimental data.

\subsubsection{Difference Method}

Values of $\lambda(T)$ can be obtained from the measured values of $X_{i}, T_{i}$ by equating the derivative $d X / d T$ to the ratio of increments $\Delta X / \Delta T(\Delta X$ and $\Delta T$ are the distances and temperature differences, respectively, between adjacent measuring positions on the specimen).

$$
\lambda(\bar{T}) \approx-\frac{\dot{Q}}{A} \frac{\Delta X}{\Delta T}
$$

This method results in seven values of $\lambda(\bar{T})$ for each run; $\bar{T}$ is the mean temperature between each adjacent pair of thermocouples.

\subsubsection{Semi-Continuous Method}

One could also represent functionally the $X_{i}, T_{i}$ data by a least squares fit to obtain the parameters, $A_{1}$, $A_{2}$, . . . $A_{m}$,

$$
X=X\left(T, A_{1}, A_{2}, \ldots . A_{m}\right) .
$$

Then upon differentiation with respect to $T$ to obtain $X^{\prime}=d X / d T$, we have

$$
\lambda(T)=-\frac{\dot{Q}}{A} X^{\prime},
$$

which yields a continuous set of values of $\lambda$ over the temperature range of each run. Of course, since each run is treated separately one would end up with a set of discontinuous curves.

\subsubsection{Continuous Method}

It would be more desirable to represent the measured data for all of the runs simultaneously. This would have the advantage of resulting in a $\lambda(T)$ function continuous over the entire range of measurement. It is also more desirable because the statistics of the least squares fit are then based upon $8 n$ points ( $n$ is the number of runs) instead of just 8 points. This can be accomplished in the following manner. In the absence of experimental errors, it is clear that one should obtain identical values of $\lambda$ (from overlapping runs) at a given temperature regardless of the value of $\dot{Q}, A$, or $X$. For two overlapping runs these variables may be different at the given temperature. Thus if we rewrite eq (2) in the form

$$
\lambda(T)=-\frac{d Z}{d T}, \quad \text { where } Z=\frac{\dot{Q} X}{A},
$$

we see that

$$
Z=Z\left(T, A_{1}, A_{2}, \ldots A_{m}\right)
$$

can differ from run to run only by a constant. Thus in general we have

$$
Z=Z_{j}\left(T, A_{1}, A_{2}, \ldots A_{m}\right)+b_{j} .
$$

The $b_{j}$, called shift factors, serve only to account for the discontinuous shifts which occur in the $Z$ versus $T$ values from run to run, and do not appear directly in the function $d Z / d T$. Thus we can fit the $8 n$ data points to determine the $m$ parameters, $A_{1}, A_{2} \ldots A_{m}$, and the $n$ - 1 shift factors, $b_{2}, b_{3}, \ldots b_{n}$. Note that the first shift factor may be arbitrarily set equal to zero. The number of degrees of freedom of the fit in the absence of other conditions is therefore $7 n-m+1$. In this experiment we have eight thermocouple measuring stations and the temperature differences between adjacent positions is generally smaller than about $10 \mathrm{~K}$, sometimes less than $1 \mathrm{~K}$. Because of these small temperature differences the results from eqs (3), (5), and (6) should be quite similar. 


\subsection{Electrical Resistivity}

The measurement of current through and voltage across the specimen determines the specimen resistance, $R$, between measuring stations 1 and 8 . Most of the measurements are made with a thermal gradient on the specimen and, since the measurement is across the entire specimen, the total span of temperature may be quite large (over $100 \mathrm{~K}$ ). Thus resistivity, $\rho$, as a function of temperature, $T$, must be obtained from measured resistances of a nonisothermal specimen. The defining equation for resistivity is

$$
R=\int_{x_{1}}^{x_{2}} \frac{\rho(T) d X}{A}
$$

\subsubsection{Mean Temperature Method}

The approach generally taken is to assume that $\rho(T)$ and $d X / d T$ are slowly varying functions over the specimen, which results in

$$
\rho(\bar{T}) \approx \bar{\rho}_{x}=\frac{R A}{x_{2}-x_{1}}, \quad \text { where } \bar{T}=\frac{T_{2}+T_{1}}{2},
$$

and $\bar{\rho}_{x}$ is the average resistivity over the specimen.

It is noted that, if large gradients exist in the specimen, eq (10) may be significantly in error. In this experiment we have measured temperatures at eight positions along the specimen thus we can compensate partially for this error by computing $\bar{T}$ from eq (11)

$$
\bar{T} \equiv \frac{\int_{x_{1}}^{x_{2}} T d X}{\int_{x_{1}}^{x_{2}} d X} \approx \frac{\sum_{i=1}^{7} \bar{T}_{i} \Delta X_{i}}{\sum_{i=1}^{7} \Delta X_{i}}
$$

where the summation extends over the seven measured segments and $\bar{T}_{i}$ is the mean temperature of the $i$ th segment. One can check the assumptions after obtaining the $\rho(\bar{T})$ curve. The $\rho(\bar{T})$ values are inserted into eq (9) and compared to the experimental data for each run. This calculation is done numerically with

$$
R \approx \sum_{i=1}^{7} \frac{\rho\left(\bar{T}_{i}\right) \Delta X_{i}}{A}
$$

The differences between values calculated from eq (12) and measured resistances will indicate whether systematic errors exist in the data representation.

\subsubsection{Approximate Integral Method}

One can use the more correct but also more complicated procedure as follows. From eq (9) we obtain

$$
R A=\int_{x_{1}}^{x_{2}} \rho(T) d x \approx \sum_{i=1}^{7} \rho\left(\bar{T}_{i}\right) \Delta X_{i}
$$

where $\bar{T}_{i}$ is the mean temperature of the $i$ th segment.
Now we assume a functional form for the resistivity versus temperature equation over the temperature range of all the measurements.

$$
\rho(T)=a_{1} f_{1}(T)+a_{2} f_{2}(T)+\ldots a_{m} f_{m}(T)
$$

where $a_{1}, a_{2} \ldots a_{m}$ are parameters and $f_{1}, f_{2} \ldots f_{m}$ are specified functions of temperature. Substituting (14) into (13) we obtain

$$
\begin{array}{r}
R A=a_{1} \sum_{i=1}^{7} f_{1}\left(\bar{T}_{i}\right) \Delta X_{i}+a_{2} \sum_{i=1}^{7} f_{2}\left(\bar{T}_{i}\right) \Delta X_{i}+\ldots \\
+a_{m} \sum_{i=1}^{7} f_{m}\left(\bar{T}_{i}\right) \Delta X_{i} .
\end{array}
$$

With the $n$ experimental values of $R(n \geqslant m)$ we may perform a least squares fit of (15) to determine the $m$ parameters, $a_{1}, a_{2} \ldots a_{m}$.

Some of the electrical resistivity measurements are carried out under isothermal conditions. For these measurements one obtains from (9) and (14)

$$
\begin{aligned}
R A=\frac{\rho(T)}{X_{2}-X_{1}}=\frac{a_{1} f_{1}(T)}{X_{2}-X_{1}}+\frac{a_{2} f_{2}(T)}{X_{2}-X_{1}} & +\ldots \\
& +\frac{a_{m} f_{m}(T)}{X_{2}-X_{1}}
\end{aligned}
$$

where $T$ is measured. Thus (15) and (16) can be used simultaneously to determine the parameters.

\subsection{Thermopower}

The problem of determining the thermopower of a specimen is similar to that for determining the electrical resistivity. The quantity measured is the Seebeck voltage, $V_{s}$, over the temperature interval $T_{1}$ to $T_{2}$. The thermopower, $S$, is defined by

$$
V_{s}=\int_{T_{1}}^{T_{2}} S d T=\bar{S}\left(T_{2}-T_{1}\right)
$$

For small gradients the equation (difference method)

$$
\bar{S}(T) \approx \frac{V_{s}}{T_{2}-T_{1}}
$$

yields a relatively accurate estimation of the thermopower at temperature $\bar{T}$. However, as the gradients become larger, if $S$ varies with $T$, this approximation becomes progressively worse. An approach which allows one to circumvent this difficulty is based on the following integral method. Assume a functional form for $S$,

$$
\begin{array}{r}
S=b_{1} g_{1}^{\prime}(T)+b_{2} g_{2}^{\prime}(T)+\ldots+b_{m} g_{m}^{\prime}(T), \\
\text { where } g_{i}^{\prime}=\frac{d g_{i}}{d T}
\end{array}
$$


Performing the integration in (17) we obtain

$$
\begin{aligned}
V_{2}=b_{1}\left[g_{1}\left(T_{2}\right)\right. & \left.-g_{1}\left(T_{1}\right)\right]+b_{2}\left[g_{2}\left(T_{2}\right)-g_{2}\left(T_{1}\right)\right] \\
& +\ldots+b_{m}\left[g_{m}\left(T_{2}\right)-g_{m}\left(T_{1}\right)\right] .
\end{aligned}
$$

Equation (20) is dependent upon the measured variables $V_{s}, T_{2}, T_{1}$, and the parameters $b_{1}, b_{2}, \ldots, b_{m}$. The $m$ parameters can be determined by least squares fitting of $n \geqslant m$ sets of measurements.

\subsection{Lorenz Ratio}

The Lorenz ratio, $L$, is defined as the product of the total thermal conductivity, $\lambda$, and electrical resistivity, $\rho$, divided by temperature, $T$,

$$
L=\frac{\rho \lambda}{T}
$$

Methods have been described to obtain $\lambda$ and $\rho$ as a function of temperature. These functions may be used directly to obtain the lorenz ratio as a function of temperature.

\section{Error Analysis}

Terms such as accuracy, uncertainty, imprecision, etc., are used with various meanings by different authors. This is due, at least in part, to the lack of rigorous definitions for some of these terms. To avoid this confusion a brief discussion of such terms is included here. This discussion is generally consistent with papers by Eisenhart [9], Natrella [10], ASTM [11], and $\mathrm{Ku}[12]$.

In this paper the words accuracy and precision will refer to a measurement process; while the word uncertainty will refer to the reported values obtained from such a process. The uncertainty of a reported value is indicated by giving credible limits within which the "true" value is to be found. There is, of course, a certain amount of risk that the true value will fall outside of these limits. The reporter's estimate of the magnitude of this risk is generally not made clear. Some authors will give limits which allow essentially no risk ( $100 \%$ confidence); others will allow large risk (say less than $50 \%$ confidence). In this paper we will consider the risk to be relatively small (about $95 \%$ confidence). The total uncertainty of a reported value is determined partly by the estimated accuracy (strickly, inaccuracy) of a measurement process, partly by how well the inaccuracy is known, and, finally, by the number of times the process is repeated.

The accuracy of a given measurement process is determined by both the random and systematic (bias) errors inherent in the measurement process. The magnitude of the total random error determines the precision (strictly, the imprecision) of the measurement. Precision thus concerns the closeness together or repeatability of measurements; while accuracy concerns closeness to what was to be measured. This implies that one must also very carefully state that which is to be measured. The usual basis of an index of precision is the standard deviation of the statistical distribution of the random errors of measurement. Unfortunately, a single comprehensive measure of accuracy (or inaccuracy), analgous to the standard deviation as a measure of imprecision, does not exist. To characterize one's knowledge of the accuracy of a measurement process it is necessary to indicate (a) limits to the systematic error or bias and the degree of confidence of the writer, and (b) the precision, using a well-defined index of precision. It is noted that the statistically precise concept of a family of confidence intervals associated with a definite confidence level is applicable only when the data are based on an adequate sampling of the total range of circumstances. It follows that these concepts are not strictly applicable when systematic errors are a significant part of the inaccuracy of the measurement process. In many experiments, including this one, it is highly impractical to accomplish an adequate sampling of the total range of circumstances, and thus a subjective estimate of the magnitude of systematic errors is necessary to describe completely the uncertainty of the results presented. It is, of course, desirable that these subjective estimates be based, as much as possible, on experimental evidence gathered under similar circumstances.

To characterize the uncertainty of a reported value, we will use the same approach as in characterizing the accuracy of a measurement process: (1) indicate limits to the probable systematic error in the final result at a subjectively estimated 95 percent confidence, (2) indicate the uncertainty of the final result due to random error by giving the 95 percent confidence interval for the mean. Note that this interval is dependent upon the number of measurements, while the standard deviation of the measurement process is not.

The total uncertainty of a reported value will be indicated by a single number obtained from the bias estimator (95\% confidence) and the equivalent 95 percent confidence level confidence interval based on the imprecision of the measurements. We have chosen to take the root-mean-square value of these independent quantities as the uncertainty of the reported data with a 95 percent confidence.

The experimental errors in this work are classed generally as temperature measurement errors and heat flow errors. Each of these can be further subdivided into systematic and random errors. Both of these affect the overall uncertainty of the results but the latter determinines the imprecision of the measurement process. Some of these errors are systematic errors on a single run but tend to become randomized over the entire sequence of measurements on a single specimen. It is desirable to randomize as many as possible of the potential systematic errors (i.e., make measurements over a larger range of circumstances) to get a better measure of the probable data uncertainty from the imprecision of the measurement process.

\subsection{Temperature Measurement Errors}

In the determination of the uncertainty of thermal conductivity and thermopower both temperature and 
temperature difference errors must be considered. In the measurement of electrical resistivity, however, only the temperature measurement errors contribute to the total uncertainty. This distinction should be noted in the following discussion.

\subsubsection{Reference Block Temperature}

The reference junction for each of the thermocouples is on the reference block. Thus any error in the temperature determination of the reference block will appear in all other measured temperatures. The reference block temperature is determined with a platinum resistance thermometer (PRT) for each of the runs except the liquid helium runs. The PRT measurements are uncertain by $0.01 \mathrm{~K}$ below $90 \mathrm{~K}$ and $0.002 \mathrm{~K}$ above $90 \mathrm{~K}$. The PRT measurement uncertainty is caused primarily by thermally and electrically induced noise. This PRT was calibrated in 1953 by NBS, Washington. In 1966 its calibration was checked by L. L. Sparks of the NBS Cryogenics Division, Boulder, Colo. The differences found at 20, 75, and $273 \mathrm{~K}$ were $-0.00057,0.00007$, and $0.0002 \Omega$, respectively. These differences were plotted and interpolations were performed on the resulting curve to obtain a new calibration for this PRT. The interpolation is uncertain to about $5 \mathrm{mK}$ in the 20 to $90 \mathrm{~K}$ range and $1 \mathrm{mK}$ in the 100 to $723 \mathrm{~K}$ range.

The reference block temperatures for the liquid helium runs are determined using the $1958 \mathrm{He}^{4}$ vapor pressure scale [8]. The temperatures obtained from the $\mathrm{He}^{4}$ vapor pressure determinations are uncertain by $0.01 \mathrm{~K}$. Neither the measurement of vapor pressure nor the temperature-pressure relation contribute a significant error. However the reference ring temperature may be slightly higher than the liquid helium temperature because of heat flow across the interface between the specimen chamber lid and the liquid helium. Also there may be a temperature discontinuity at the liquid-gas surface and some stratification in the liquid resulting in actual temperatures slightly different (possibly as much as $0.01 \mathrm{~K}$ ) than the measured temperatures. Neither of these effects produces a systematic error in the case of the PRT measurements at higher temperatures, since the PRT is mounted directly on the reference block.

The thermal tempering calculations indicate that the thermocouple reference junctions are within $1 \mathrm{mK}$ of the reference block.

\subsubsection{Specimen Temperatures}

The measured specimen temperatures may be in error for several reasons. Thermocouple calibration errors, specimen temperature disturbances caused by the attachment of thermocouples, thermocouple contact resistance, extraneous thermal emfs, and reference block temperature measurement errors are contributing factors to the total specimen temperature error. As pointed out in section 2.1, the thermocouple calibration is determined from the standard table as modified by spot calibrations for these specific spools of wire. The calibration uncertainties of the standard table are reported by Sparks et al. [4] as less than $0.015 \mathrm{~K}$. The interpolation-calibration uncertainty of the subsequent spool calibration is somewhat larger. The deviations between the spool calibration and the standard table are shown in figure 4 . Interpolations from figure 4 are uncertain by $1 \mu \mathrm{V}$ between 4 and $20 \mathrm{~K}$ and $2 \mu \mathrm{V}$ between the higher temperature calibration points. The interpolation error will be greatest midway between the calibration points. This corresponds to a maximum absolute temperature uncertainty of about $0.1 \mathrm{~K}$ and a relative temperature difference uncertainty of 0.5 percent between 4 and $20 \mathrm{~K}, 0.2$ percent between 20 and $76 \mathrm{~K}$, and 0.1 percent above $76 \mathrm{~K}$. Another source of error is present since all thermocouples are represented by a single calibration table. Real differences undoubtedly exist between these thermocouples; however, as indicated previously, these differences are less than $1 \mu \mathrm{V}$, even for a temperature interval from 4 to $300 \mathrm{~K}$.

The magnitude of the temperature disturbance caused by the thermocouple attachment will be small if the shell temperature is adjusted to minimize heat flow along the thermocouples to the sample. This adjustment also minimizes the problem introduced by thermal contact resistance between the specimen and the thermocouples. It is difficult to assess the effect of these errors separately. Errors caused by these effects, combined with conduction and radiation losses, are considered in a later section.

Extraneous thermal emf in the thermocouple leads is in part eliminated by considering the isothermal zero readings previously mentioned. Experimentally these zero readings are found to consist of a fixed component and a smaller variable component. The former is probably caused by the general environment of the apparatus and the latter by short-term temperature fluctuations in the apparatus. The fixed component of the zero readings is eliminated by subtracting it from the experimental data in the presence of a gradient. The variable component contributes about $0.01 \mathrm{~K}$ to experimental imprecision in the temperature differences.

The total uncertainty in temperature and temperature difference is taken as the root mean square of the above components. This method of propagating errors is valid for independent errors [12]. The possible error in temperature, primarily of a systematic nature, may be as high as $0.10 \mathrm{~K}$ above $20 \mathrm{~K}$ and 0.5 percent of temperature below $20 \mathrm{~K}$. The uncertainty in temperature differences contains both systematic and random components. The systematic errors in $\Delta T$ may approach 0.5 percent of $\Delta T$ between 4 and $20 \mathrm{~K}, 0.2$ percent of $\Delta T$ between 20 and $76 \mathrm{~K}$, and 0.1 percent of $\Delta T$ above $76 \mathrm{~K}$. The uncertainty in $\Delta T$ due to random error is about $0.01 \mathrm{~K}$.

\subsection{Heat Flow Errors}

The rate of heat generated by the heater at the bottom of the specimen is calculated from potentiometric measurements of voltage and current. Not all of this heat flows up the specimen. Some is lost, by conduction, through connecting leads, glass fiber 
packing, and gas. Some is lost, by radiation, to the shell and other components in the specimen chamber. Some heat is also effectively lost or gained due to temperature drift and the associated enthalpy changes of the specimen assembly.

\subsubsection{Conduction Losses}

The heat lost by conduction has been directly measured at low temperatures where radiation losses are negligible. These measurements, accomplished by heating up the shell a known amount with respect to the specimen, indicate a loss or gain of about 0.01 $\mathrm{mW}$ per degree difference between shell and specimen. These losses increase with temperature due to the increase of the thermal conductivity of the connecting components. This measured value agrees with the calculated value to within the combined uncertainty of both values $(50 \%)$. It has been found experimentally that this heat loss amounts to a small fraction $(<0.1 \%)$ of the total heat flow for a typical gradient and specimen-to-shell temperature difference which are $1 \mathrm{mK}$ at the bottom of the specimen and $0.1 \mathrm{~K}$ at the top.

\subsubsection{Radiation Losses}

An upper limit has been established for the radiation loss from the specimen. This calculation is based upon a knowledge of the thermal conductivity (including radiation transfer) of the glass fiber packing. The thermal conductivity of glass fiber as a function of packing density was reported by Christiansen et al. $[13,14]$. They determined room temperature $(300 \mathrm{~K})$ conductivities of 0.0065 and $0.0011 \mathrm{Wm}^{-1} \mathrm{~K}^{-1}$ at fiber densities of $1 / 2$ and $15 \mathrm{lb} / \mathrm{ft}^{3}\left(8.1\right.$ to $\left.243 \mathrm{~kg} / \mathrm{m}^{3}\right)$ respectively. At $190 \mathrm{~K}$ the measured values were 0.0048 and $0.00056 \mathrm{Wm}^{-1} \mathrm{~K}^{-1}$ at 8.1 and $243 \mathrm{~kg} / \mathrm{m}^{3}$ respectively. However the measurements at $190 \mathrm{~K}$ were done with an enclosure emissivity of about 0.9 while at $300 \mathrm{~K}$ the emissivity was 0.2 . Thus the decrease in thermal conductivity from 300 to $190 \mathrm{~K}$ was not as great as if the emissivities had been the same in both cases. The fiber density in this thermal conductivity apparatus was about $5 \mathrm{~kg} / \mathrm{m}^{3}$ during the earlier measurements. By varying the shell-to-specimen temperature, data was obtained which resulted in a rough measure of the thermal conductivity of the glass fiber at $300 \mathrm{~K}$. The value obtained, $0.008 \mathrm{Wm}^{-1} \mathrm{~K}^{-1}$, is in reasonable agreement with the data by Christiansen et al. $[13,14]$. In later measurements the packing density was increased to about $50 \mathrm{~kg} / \mathrm{m}^{3}$. The radiation losses that exist due to temperature differences between the specimen and shell are on the order of 1 $\mathrm{mW}$ per degree difference at $300 \mathrm{~K}$. However, if the shell is maintained at nearly the same temperature distribution as the specimen, we need not be concerned about this. We do need to consider the radiation loss through the glass fiber parallel to the specimen, part of which comes from the specimen assembly and part from the shell. Assuming that the ratio of these heat losses is proportional to the ratios of the areas of each part we can establish an upper limit to the percentage heat loss of the specimen as a function of the product $\lambda A$ of the specimen at $300 \mathrm{~K}$ and at $190 \mathrm{~K}$. Table 1 contains these upper limits at fiber densities of 8.1 and $243 \mathrm{~kg} / \mathrm{m}^{3}$. The ratio of shell-tospecimen surface areas (including specimen heater, thermocouple holders, and leads) is taken as constant at $4: 1$.

TABLE 1. Radiation losses

\begin{tabular}{l|c|c|c|c}
\hline \hline \multirow{2}{*}{$\begin{array}{c}\text { Specimen } \\
\lambda A\left(\mathrm{WmK}^{-1}\right)\end{array}$} & \multicolumn{4}{|c}{ Percent radiation loss* } \\
\cline { 2 - 5 } & \multicolumn{2}{|c|}{$190 \mathrm{~K}$} & \multicolumn{2}{c}{$300 \mathrm{~K}$} \\
\cline { 2 - 5 } & $8.1 \mathrm{~kg} / \mathrm{m}^{3}$ & $243 \mathrm{~kg} / \mathrm{m}^{3}$ & $8.1 \mathrm{~kg} / \mathrm{m}^{3}$ & $243 \mathrm{~kg} / \mathrm{m}^{3}$ \\
\hline \multirow{2}{*}{$1 \times 10^{-4}$} & 1.6 & 0.2 & 13.0 & 1.6 \\
2 & 0.8 & .1 & 6.4 & 0.8 \\
4 & .4 & .05 & 3.2 & .4 \\
6 & .25 & .03 & 2.0 & .3 \\
8 & .20 & .025 & 1.6 & .2 \\
$10 \times 10^{-4}$ & .15 & .020 & 1.2 & .2 \\
\hline
\end{tabular}

*These values are based on data reported by Christiansen et al. [13, 14], enclosure emissivity $=0.9$

The value of $\lambda A$ for the measurements reported here is $8 \times 10^{-4} \mathrm{~W} \mathrm{mK}^{-1}$ at $300 \mathrm{~K}$. Thus the radiation error with a packing density of $50 \mathrm{~kg} / \mathrm{m}^{3}$ is estimated to be less than 2 percent at $300 \mathrm{~K}$. At $200 \mathrm{~K}$ this error is less than 0.2 percent.

\subsubsection{Temperature Drift Effects}

As the temperature of the specimen assembly varies, the heat content or enthalpy of the assembly changes. These enthalpy variations represent corresponding changes in the rate of heat flow at a given point in the specimen. The obvious solution to this problem is to obtain true steady state conditions. Of course it is experimentally impossible to do this exactly and so one must design the system such that the effect of maximum temperature drift rates at "steady state" is tolerable. The amount of heat per unit time, $\dot{Q}_{\text {drift }}$, absorbed or liberated by the specimen assembly due to a temperature drift of $d T / d t$ can be estimated from

$$
\begin{aligned}
\dot{Q}_{\text {drift }}=\sum\left(C m \frac{d T}{d t}\right)= & \left(C m \frac{d T}{d t}\right)_{\substack{\text { heater } \\
\text { block }}} \\
& +\left(C m \frac{d T}{d t}\right)_{\text {sample }}+\left(C m \frac{d T}{d t}\right)_{\substack{\text { thermo- } \\
\text { couple } \\
\text { holders }}}
\end{aligned}
$$

where $C$ is specific heat and $m$ is mass. The specific heat of these materials changes greatly between 4 and $300 \mathrm{~K}$. The largest specific heats occur at $300 \mathrm{~K}$ and thus the severest restriction on the tolerable $d T / d t$ will be seen at $300 \mathrm{~K}$. The mass of the aluminum heater block is 15 g. The mass of the eight thermocouple holders varies from 15 to $45 \mathrm{~g}$ depending on specimen size. The cross-sectional areas of the various specimens are adjusted in accordance to their relative conductivities so that the rate of heat flow is about the same for a given temperature and temperature gradient. However specimens larger than about $2 \mathrm{~cm}$ diameter cannot be used in this apparatus. A specimen of a 
low-conductivity alloy represents the worst case, i.e., smallest heat flow for a given gradient and largest heat capacity. The rate of heat flow to produce a small (say $10 \mathrm{~K}$ ) temperature difference across this entire sample at $300 \mathrm{~K}$ is $0.04 \mathrm{~W}$. The mass of a low-conductivity specimen is about $200 \mathrm{~g}$. To insure that enthalpy changes of the specimen assembly are less than say 0.5 percent of $0.04 \mathrm{~W}$ we obtain

$$
\frac{d T}{d t} \leqslant .0015 \mathrm{~K} / \mathrm{hr}
$$

or for type KP versus Au-Fe thermocouples

$$
\frac{d E}{d t} \leqslant 0.03 \mu \mathrm{V} / \mathrm{hr}
$$

Thus the control system on the floating sink must be stable to within about $0.0015 \mathrm{~K} / \mathrm{hr}$ and the measuring instrumentation must be capable of detecting changes in thermocouple emfs of $0.03 \mu \mathrm{V} / \mathrm{hr}$. In each case this represents approximately the limitation of these systems.

In summary, we can say that at low temperature (below $100 \mathrm{~K}$ ) the uncertainty in the amount of heat flowing in the specimen is negligible $(<0.1 \%)$ if the temperature of the specimen is steady to within the limitations of this instrumentation $(0.0015 \mathrm{~K} / \mathrm{hr})$ and if the shell-to-specimen temperature difference is less than $0.1 \mathrm{~K}$. Above $100 \mathrm{~K}$ radiation heat transfer parallel to the specimen becomes important. For Inconel 718 the radiation heat loss may be as much as as 2 percent even if the shell temperature matches the specimen temperature. If a shell-to-specimen mismatch occurs, radiation perpendicular to the specimen will introduce a heat loss of about $20 \mathrm{~mW}$ per degree difference.

\subsection{Dimensional and Measuring System Errors}

The errors in measuring cross-sectional area and thermocouple position are relatively small. The uncertainty in the diameter determinations is less than $0.0001 \mathrm{~cm}$, which for the smallest specimen measured $\left(0.1 \mathrm{~cm}^{2}\right.$ cross-sectional area) corresponds to 0.03 percent. The position of the thermocouples is measured to within $0.0001 \mathrm{~cm}$. The separation between adjacent thermocouples $(2.54 \mathrm{~cm})$ is therefore accurate to within 0.004 percent. The properties presented in this paper are with respect to the room temperature dimensions of the specimen. If the properties at the true dimensions are desired, small corrections must be applied for contraction of the specimens upon cooling. This correction is on the order of 0.1 percent at $4 \mathrm{~K}$ for these specimens. The uncertainties introduced by the measuring instruments are also in general negligible compared to other uncertainties in the system. The thermocouple and specimen resistance voltages are measured to within $0.01 \mu \mathrm{V}$. The specimen heater voltage and current are measured to better than 0.01 percent. The PRT voltages and currents are measured to better than 0.01 percent, except near $20 \mathrm{~K}$ where the uncertainty in PRT voltages is 0.1 percent. The limitations in these measurements is caused primarily by electrical noise in the system.

\subsection{Precision, Accuracy, and Uncertainty}

The primary objective of the preceding error analysis is to obtain estimates of limits to the probable systematic errors in this measurement process. The expected imprecision of the measurement process also may be estimated from this analysis; however, a more reliable estimate of the imprecision is obtained from a statistical analysis of the experimental results. The estimated systematic errors of the properties reported here are obtained through the use of error propagation formulas [12] and the estimated systematic errors in the measured variables. Considerable experimental effort has been directed toward assessing the validity of these estimates. Runs have been repeated; runs have been conducted with overlapping temperature ranges at a given reference block temperature and also with different reference block temperatures; in some cases the specimen has been measured, removed, reassembled, and remeasured; the effect of shellto-specimen temperature differences has been investigated; to randomize systematic thermocouple calibration errors, eight thermocouples were used along the specimen instead of only two or three; the effect of specimen temperature drift has been experimentally investigated. These investigations and the design of the apparatus result in a high degree of confidence in our error estimates.

The estimated limit to systematic error in thermal conductivity, caused primarily by error in determination of heat flow and temperature difference, is 2 percent at $300 \mathrm{~K}$ decreasing to 0.2 percent at $200 \mathrm{~K}$, 0.2 percent from $200 \mathrm{~K}$ to $50 \mathrm{~K}$ increasing to 1 percent at $4 \mathrm{~K}$. The estimated systematic error in electrical resistivity is 0.05 percent below $30 \mathrm{~K}$ and 0.1 percent at higher temperatures. At low temperatures the electrical resistivity becomes essentially independent of temperature and thus the systematic errors are primarily due to dimensional errors.

The limit to systematic error in thermopower with respect to the reference material (normal silver) is estimated to be less than 0.5 percent $+0.01 \mu \mathrm{V} / \mathrm{K}$ at $4 \mathrm{~K}$, falling to 0.2 percent $+0.01 \mu \mathrm{V} / \mathrm{K}$ at $30 \mathrm{~K}$, and to 0.1 percent $+0.01 \mu \mathrm{V} / \mathrm{K}$ above $76 \mathrm{~K}$.

Estimates of the standard deviations of the measurement processes for thermal conductivity, electrical resistivity, and thermovoltage are obtained from all of the data obtained at this time. The standard deviation of the measurement process is computed from the variance of the least squares fit, i.e., the sum of the squares of the residuals divided by the degrees of freedom. The standard deviation of the thermal conductivity measurement is 1.0 percent of the conductivity based on values ranging from 0.7 to 1.7 percent for various specimens. The standard deviation of the electrical resistance measurement depends strongly on the resistivity of the specimens. The standard deviation for the better conductors is about 0.1 percent. For the poorer conductors the standard deviation of 
the electrical resistance measurement is about 0.01 percent. The larger deviations can be reduced somewhat by using a larger electrical current through the good conductors; however, care must be exercised to avoid transient heating effects caused by the power dissipation in the small connecting leads. The standard deviation of the thermovoltage measurements is 0.1 $\mu \mathrm{V}$ based on values ranging from 0.04 to $0.14 \mu \mathrm{V}$ for the various specimens.

Estimates of the standard errors of the reported calculated values for thermal conductivity, electrical resistivity, and thermopower are calculated from the variance-covariance matrix of the parameters determined by least squares fit for each of the data sets. The method of calculation is given by Natrella [10] (Standard deviation of a predicted point, pp. 6-12). The computed values are temperature dependent and vary from specimen to specimen; average values of the standard error are 0.25 percent for thermal conductivity and 0.1 percent for electrical resistivity at low temperatures and 0.05 percent at high temperatures. The standard error for thermopower varies from 0.1 $\mu \mathrm{V} / \mathrm{K}$ at the lower temperatures to $0.003 \mu \mathrm{V} / \mathrm{K}$ at the higher temperatures.

Based on these estimates of limits to systematic bias and standard error, we estimate (with 95\% confidence) the uncertainty in thermal conductivity to be 2.5 percent at $300 \mathrm{~K}$, decreasing to 0.70 percent at $200 \mathrm{~K}, 0.70$ percent from $200 \mathrm{~K}$ to $50 \mathrm{~K}$, increasing to 1.5 percent at $4 \mathrm{~K}$. The uncertainty in electrcial resistivity is 0.25 percent. Thermopower uncertainty is estimated as 0.5 percent $+0.2 \mu \mathrm{V} / \mathrm{K}$ at $4 \mathrm{~K}, 0.2$ percent $+0.05 \mu V / K$ at $30 \mathrm{~K}$, and 0.1 percent +0.03 $\mu \mathrm{V} / \mathrm{K}$ above $76 \mathrm{~K}$.

\section{Specimen Characterization}

An Armco iron rod (2.54 cm diam and $35.6 \mathrm{~cm}$ long) was obtained from Battelle Memorial Institute. This rod is from the same lot of stock as the specimens measured at several other laboratories $[15,20]$. We did not redetermine the composition of this rod in view of the repeated determinations by other investigators $[15,18,19,20]$. The composition, given by R. W. Powell [18], of Armco iron in weight percent is: 0.02 C, $0.03 \mathrm{Mn}, 0.006 \mathrm{P}, 0.023 \mathrm{~S}, 0.004 \mathrm{Si}, 0.08 \mathrm{Cu}, 0.08$ $\mathrm{Ni}$, and $99.8 \mathrm{Fe}$. This rod was annealed by the supplier as follows: $1 / 2 \mathrm{hr}$ at $870{ }^{\circ} \mathrm{C}$ in a gas-heated air muffle, and then in a quartz capsule at $1 \times 10^{-6}$ torr for $1 \frac{1}{2} \mathrm{hr}$, at $875{ }^{\circ} \mathrm{C}$, furnace cooled to $150{ }^{\circ} \mathrm{C}$, held at $150{ }^{\circ} \mathrm{C}$ for $24 \mathrm{hr}$, and furnace cooled to room temperature. We cut the rod into quarters along its axis and cut a 5-cm-long piece from each end of each quadrant. These eight pieces were used for electrical residual resistivity ratio, hardness, and grain size measurements. Two of the center $25-\mathrm{cm}$ sections were measured in the thermal conductivity apparatus. These specimens were chosen on the basis of the electrical resistivity measurements to maximize the difference between them. The division of the rod and the labeling of specimens are shown in figure 6 .

The hardness of these specimens, after machining, was B-40.0. The specimens were subsequently re-

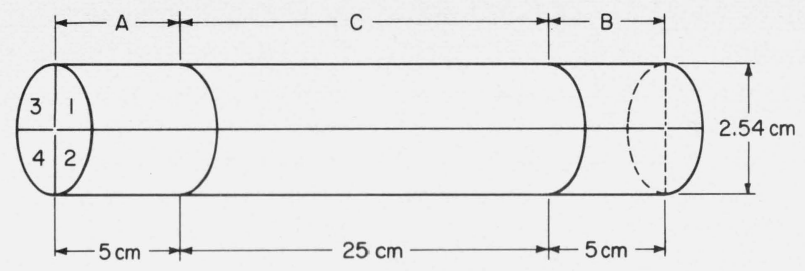

Figure 6. Division of Armco iron rod.

Each of the 12 pieces shown was machined into a circular cylinder for measurement.

annealed using the same procedure indicated by the supplier. The hardness after anneal was B-37.1. The grain size approximated from ASTM Chart E112, plate 1 was $0.053 \mathrm{~mm}$ and $0.064 \mathrm{~mm}$ after machining and after reannealing, respectively.

The electrical residual resistivity ratios, $\rho_{273 \mathrm{~K}} / \rho_{4 \mathrm{~K}}$ of the eight specimens (1A . . 4A, 1B ...4B) after machining and of two of these specimens after reannealing are recorded in table 2. These ratios, obtained from electrical resistance measurements at $273 \mathrm{~K}$ and $4 \mathrm{~K}$ in a specially fabricated dip probe, are estimated to be accurate to about 0.5 percent. Table 2 also contains the resistivity ratios of specimens $2 \mathrm{C}$ and $4 \mathrm{C}$. The data marked with asterisks were obtained from the thermal conductivity apparatus.

C. F. Lucks of Battelle Memorial Institute performed similar measurements on another bar of Armco iron [21]. The spread of his results on six specimens is \pm 8.5 percent of the mean while the spread of our 10 specimens is \pm 6.5 percent. The mean value of the residual resistivity ratio (13.65) determined from our data is 5.5 percent below the mean value measured by Lucks. It is noted from table 1 that the residual resistivity ratios are lower after annealing. This is probably caused by diffusion of impurities from the grain boundaries upon heat treatment. Impurities in solution are more effective electron scatterers than impurity precipitates at grain boundaries. Residual resistivity ratios reported by other investigators are also included in table 2.

TABLE 2. Residual resistivity ratio $\left(\rho_{273 \kappa} / \rho_{4 \kappa}\right)$ of Armco iron

\begin{tabular}{c|c|c}
\hline \hline Specimen & After machining & After annealing \\
\hline 1A & 14.12 & \\
2A & 13.81 & \\
3A & 14.13 & \\
4A & 12.99 & 12.88 \\
1B & 13.81 & 11.52 \\
2B & 14.51 & $12.57^{*}$ \\
3B & 14.09 & \\
4B & 12.77 & \\
2C & 13.86, & \\
& $13.93^{*}$ & \\
4C & 12.44, & \\
& $12.53^{*}$ & \\
\hline
\end{tabular}

*These values were determined from measurements using the thermal conductivity apparatus.

\begin{tabular}{lc}
\multicolumn{1}{c}{ Source } & $\rho_{273 \kappa} / \rho_{4 \kappa}$ \\
\hline Lucks [21] & 12.5 to 14.7 \\
Fulkerson et al. [15] & $9.8,10.0$ \\
Shanks et al. [19] & 12.6
\end{tabular}




\section{Results}

The transport properties of specimens $2 \mathrm{C}$ and $4 \mathrm{C}$ were measured in the thermal conductivity apparatus. Specimen 2C was subsequently annealed (same annealing procedure as described before) and remeasured.

The data analysis methods used, of those described in section 4, are (a) the difference method for thermal conductivity, (b) the approximate integral method for electrical resistivity, and (c) the integral method for thermopower. The other methods described were also tried; but for various reasons they were discarded in favor of those indicated above. The experimental data were functionally represented with the following arbitrarily chosen equations:

$$
\begin{aligned}
\ln \lambda & =\sum_{i=1}^{n} a_{i}[\ln T]^{i+1} \\
\rho & =\sum_{i=1}^{m} b_{i}[\ln T]^{i-1} \\
S & =\sum_{i=1}^{l} c_{i}\left[\ln T^{\prime}\right]^{i} / T^{\prime} ; \quad T^{\prime}=\frac{T}{10}+1
\end{aligned}
$$

where $\lambda=$ thermal conductivity, $\rho=$ electrical resistivity, $S=$ thermopower, and $T=$ temperature. Temperatures are based on the IPTS- 68 scale above $20 \mathrm{~K}$ and the NBS P2-20 (1965) scale below $20 \mathrm{~K}$. The parameters, $a_{i}, b_{i}$, and $c_{i}$, determined by least squares, are presented in tables 3,4 , and 5 . The number of terms used to represent each of the data sets is optimized, through the use of orthonormal functions, so that none of the precision of the data is lost by "underfitting" nor are any necessary oscillations introduced by "overfitting."

The following is a brief description of the method used. The overdetermined set of equations is formed from the experimental data and by the appropriate equations $(22,23$, or 24$)$, using 16 terms in each equation. This set of equations was converted to an orthonormal system according to the Bjorck modification of the Gram-Schmidt orthogonalization procedure [22]. The 16 orthonormal coefficients for these orthonormal functions are then obtained for the best fit of the data.

TABle 3. Parameters in equations (22), (23), and (24) for Armco iron, specimen $2 C$

\begin{tabular}{r|c|r|r}
\hline \hline$i$ & $\begin{array}{c}\text { Thermal } \\
\text { conductivity } \\
\text { coefficients }\end{array}$ & $\begin{array}{c}\text { Electrical } \\
\text { resistivity } \\
\text { coefficients }\end{array}$ & \multicolumn{1}{c}{$\begin{array}{c}\text { Thermopower } \\
\text { coefficients }\end{array}$} \\
\hline 1 & 4.51614994 & $-4.95025810 \times 10^{-7}$ & $-3.44881675 \times 10^{2}$ \\
2 & -4.13926935 & $1.65473929 \times 10^{-6}$ & $2.37913833 \times 10^{3}$ \\
3 & 2.07599685 & $-2.37099406 \times 10^{-6}$ & $-6.68364762 \times 10^{3}$ \\
4 & $-8.61606749 \times 10^{-1}$ & $1.93668635 \times 10^{-6}$ & $9.99411766 \times 10^{3}$ \\
5 & $3.39315321 \times 10^{-1}$ & $-9.93191337 \times 10^{-7}$ & $-8.67747098 \times 10^{3}$ \\
6 & $-9.99896812 \times 10^{-2}$ & $3.31399468 \times 10^{-7}$ & $4.46376537 \times 10^{3}$ \\
7 & $1.79360964 \times 10^{-2}$ & $-7.18946332 \times 10^{-8}$ & $-1.32173829 \times 10^{3}$ \\
8 & $-1.71155124 \times 10^{-3}$ & $9.77121499 \times 10^{-9}$ & $2.08103179 \times 10^{2}$ \\
9 & $6.66070951 \times 10^{-5}$ & $-7.54546890 \times 10^{-10}$ & $-1.35462989 \times 10^{1}$ \\
10 & & $2.52377946 \times 10^{-11}$ & \\
\hline
\end{tabular}

TABle 4. Parameters in equations (22), (23), and (24) for Armco iron, specimen $2 C$ after annealing

\begin{tabular}{r|c|r|r}
\hline \hline$i$ & $\begin{array}{c}\text { Thermal } \\
\text { conductivity } \\
\text { coefficients }\end{array}$ & $\begin{array}{c}\text { Electrical } \\
\text { resistivity } \\
\text { coefficients }\end{array}$ & $\begin{array}{c}\text { Thermopower } \\
\text { coefficients }\end{array}$ \\
\hline 1 & 7.43890940 & $-4.20510751 \times 10^{-7}$ & $-5.10933863 \times 10^{2}$ \\
2 & $-1.14675555 \times 10^{1}$ & $1.45081937 \times 10^{-6}$ & $3.36812410 \times 10^{3}$ \\
3 & 9.73124560 & $-2.12826875 \times 10^{-6}$ & $-9.06609424 \times 10^{3}$ \\
4 & -5.28250471 & $1.77366602 \times 10^{-6}$ & $1.30552541 \times 10^{4}$ \\
5 & 1.89245802 & $-9.25249389 \times 10^{-7}$ & $-1.09917641 \times 10^{4}$ \\
6 & $-4.41102771 \times 10^{-1}$ & $3.13228379 \times 10^{-7}$ & $5.52800895 \times 10^{3}$ \\
7 & $6.37973455 \times 10^{-2}$ & $-6.87884712 \times 10^{-8}$ & $-1.61455399 \times 10^{3}$ \\
8 & $-5.17020759 \times 10^{-3}$ & $9.44600166 \times 10^{-9}$ & $2.52389423 \times 10^{2}$ \\
9 & $1.78835874 \times 10^{-4}$ & $-7.35822503 \times 10^{-10}$ & $-1.63749922 \times 10^{1}$ \\
10 & & $2.47951038 \times 10^{-11}$ & \\
\hline
\end{tabular}

TABle 5. Parameters in equations (22), (23), and (24) for Armco iron, specimen $4 C$

\begin{tabular}{r|c|c|r}
\hline \hline$i$ & $\begin{array}{c}\text { Thermal } \\
\text { conductivity } \\
\text { coefficients }\end{array}$ & $\begin{array}{c}\text { Electrical } \\
\text { resistivity } \\
\text { coefficients }\end{array}$ & $\begin{array}{c}\text { Thermopower } \\
\text { coefficients }\end{array}$ \\
\hline 1 & 8.21226100 & $-5.03088441 \times 10^{-7}$ & $-6.42943844 \times 10^{2}$ \\
2 & $-1.32577224 \times 10^{1}$ & $1.69059561 \times 10^{-6}$ & $4.14540857 \times 10^{3}$ \\
3 & $1.14738701 \times 10^{1}$ & $-2.42733181 \times 10^{-6}$ & $-1.09289158 \times 10^{4}$ \\
4 & -6.21776147 & $1.98402296 \times 10^{-6}$ & $1.54381788 \times 10^{4}$ \\
5 & 2.19527810 & $-1.01722378 \times 10^{-6}$ & $-1.27838650 \times 10^{4}$ \\
6 & $-5.01619108 \times 10^{-1}$ & $3.39158569 \times 10^{-7}$ & $6.34295244 \times 10^{3}$ \\
7 & $7.10720281 \times 10^{-2}$ & $-7.35034919 \times 10^{-8}$ & $-1.83456286 \times 10^{3}$ \\
8 & $-5.64940725 \times 10^{-3}$ & $9.97927431 \times 10^{-9}$ & $2.84809534 \times 10^{2}$ \\
9 & $1.91995267 \times 10^{-4}$ & $-7.69854134 \times 10^{-10}$ & $-1.83820643 \times 10^{1}$ \\
10 & & $2.57278514 \times 10^{-11}$ & \\
\hline
\end{tabular}

The absolute magnitude of each coefficient is indicative of the relative significance of the corresponding term and also directly indicates the average absolute magnitude of that term. This is so since the sum of squares of each orthonormal function is unity over the data set. A plot of the absolute magnitudes of orthonormal coefficients versus the term number will usually exhibit a generally decreasing character until the noise level of the data is reached, and then fluctuate about that value. The point at which the noise level is reached indicates the number of terms one should retain in the function in order to best fit the data with this function. This test procedure is similar to, but more straightforward and more intuitively desirable than, a statistical test such as the $F$-test. From these orthonormal coefficients and functions one obtains the coefficients (parameters) of the original equation. In this work the original equation is also fitted to the data using the more common procedure in which one establishes the so-called normal equations and obtains the least squares coefficients by the Gauss-Jordan matrix inversion routine [23]. Since the coefficients for a least squares fit must be unique, disagreement between these two independently obtained sets of coefficients is used to detect the presence of significant round-off error. Round-off error is absent to nine significant figures in the coefficients presented here.

Values of $\lambda, \rho, L$, and $S$ are given in tables 6,7 , and 8 as computed from eqs (22), (23), and (24). A complete 
listing of all raw experimental data is contained in an NBS report for future reference.

\section{Discussion}

The thermal conductivities of these three Armco iron specimens cut from one rod differ by as much as 10 percent at low temperatures; the differences observed in electrical resistivity are similar. The thermal conductivity deviations of the three sets of values are shown in figure 7 . In figure $7, \bar{\lambda}$ is the mean thermal conductivity for the three specimens at temperature, $T$. These data seem to indicate that Armco iron is a poor thermal conductivity standard material at low temperatures. Since Armco iron is already in extensive use as

TABle 6. Transport properties of Armco iron, specimen $2 C$

\begin{tabular}{|c|c|c|c|c|}
\hline $\begin{array}{l}\text { Temper- } \\
\text { ature }\end{array}$ & $\begin{array}{c}\text { Thermal } \\
\text { conductivity }\end{array}$ & $\begin{array}{l}\text { Electrical } \\
\text { resistivity }\end{array}$ & $\begin{array}{l}\text { Lorenz } \\
\text { ratio } \times 10^{8}\end{array}$ & $\begin{array}{l}\text { Thermo- } \\
\text { power }\end{array}$ \\
\hline$K$ & $W m^{-1} K^{-1}$ & $\mu \Omega m$ & $V^{2} / K^{2}$ & $\mu V / K$ \\
\hline 6 & 21.7 & 0.006905 & 2.49 & 0.02 \\
\hline 7 & 25.6 & .006903 & 2.52 & .06 \\
\hline 8 & 29.2 & .006911 & 2.53 & .07 \\
\hline 9 & 32.8 & .006920 & 2.53 & .06 \\
\hline 10 & 36.4 & .006926 & 2.52 & .07 \\
\hline 12 & 43.5 & .006929 & 2.51 & .13 \\
\hline 14 & 50.7 & .006932 & 2.51 & .22 \\
\hline 16 & 57.9 & .006941 & 2.51 & .32 \\
\hline 18 & 65.0 & .006957 & 2.51 & .43 \\
\hline 20 & 71.8 & .006981 & 2.50 & .54 \\
\hline 25 & 87.0 & .007067 & 2.46 & .82 \\
\hline 30 & 98.9 & .007196 & 2.37 & 1.18 \\
\hline 35 & 107 & .007386 & 2.26 & 1.67 \\
\hline 40 & 113 & .007664 & 2.16 & 2.28 \\
\hline 45 & 115 & .008051 & 2.06 & 3.00 \\
\hline 50 & 116 & .008562 & 1.99 & 3.79 \\
\hline 55 & 115 & .009202 & 1.93 & 4.63 \\
\hline 60 & 114 & .009976 & 1.89 & 5.51 \\
\hline 65 & 112 & .01088 & 1.87 & 6.38 \\
\hline 70 & 110 & .01191 & 1.87 & 7.24 \\
\hline 75 & 107 & .01306 & 1.87 & 8.07 \\
\hline 80 & 105 & .01432 & 1.88 & 8.86 \\
\hline 85 & 103 & .01568 & 1.89 & 9.60 \\
\hline 90 & 100 & .01713 & 1.91 & 10.30 \\
\hline 95 & 98.4 & .01867 & 1.93 & 10.95 \\
\hline 100 & 96.6 & .02028 & 1.96 & 11.54 \\
\hline 110 & 93.4 & .02371 & 2.01 & 12.58 \\
\hline 120 & 90.8 & .02736 & 2.07 & 13.44 \\
\hline 130 & 88.7 & .03119 & 2.13 & 14.13 \\
\hline 140 & 87.1 & .03516 & 2.19 & 14.67 \\
\hline 150 & 85.8 & .03923 & 2.24 & 15.07 \\
\hline 160 & 84.7 & .04340 & 2.30 & 15.37 \\
\hline 170 & 83.9 & .04765 & 2.35 & 15.57 \\
\hline 180 & 83.1 & .05196 & 2.40 & 15.69 \\
\hline 190 & 82.4 & .05633 & 2.44 & 15.74 \\
\hline 200 & 81.8 & .06077 & 2.48 & 15.73 \\
\hline 220 & 80.5 & .06983 & 2.55 & 15.56 \\
\hline 240 & 79.1 & .07918 & 2.61 & 15.23 \\
\hline 260 & 77.5 & .08888 & 2.65 & 14.77 \\
\hline 280 & 75.9 & .09903 & 2.68 & 14.19 \\
\hline 300 & 74.3 & .10970 & 2.72 & 13.51 \\
\hline
\end{tabular}

TABLE 7. Transport properties of Armco iron, specimen $2 C$, after annealing

\begin{tabular}{|c|c|c|c|c|}
\hline $\begin{array}{l}\text { Temper- } \\
\text { ature }\end{array}$ & $\begin{array}{c}\text { Thermal } \\
\text { conductivity }\end{array}$ & $\begin{array}{l}\text { Electrical } \\
\text { resistivity }\end{array}$ & $\begin{array}{c}\text { Lorenz } \\
\text { ratio } \times 10^{8}\end{array}$ & $\begin{array}{l}\text { Thermo- } \\
\text { power }\end{array}$ \\
\hline K & $W m^{-1} K^{-1}$ & $\mu \Omega m$ & $V^{2} / K^{2}$ & $\mu V / K$ \\
\hline 6 & 19.7 & 0.007645 & 2.52 & -0.02 \\
\hline 7 & 23.2 & .007645 & 2.53 & .08 \\
\hline 8 & 26.6 & .007658 & 2.54 & .11 \\
\hline 9 & 29.9 & .007669 & 2.55 & .11 \\
\hline 10 & 33.2 & .007674 & 2.55 & .11 \\
\hline 12 & 39.8 & .007676 & 2.54 & .15 \\
\hline 14 & 46.4 & .007676 & 2.54 & .23 \\
\hline 16 & 52.9 & .007685 & 2.54 & .33 \\
\hline 18 & 59.4 & .007702 & 2.54 & .44 \\
\hline 20 & 65.6 & .007726 & 2.53 & .56 \\
\hline 25 & 79.8 & .007812 & 2.49 & .87 \\
\hline 30 & 91.2 & .007936 & 2.41 & 1.25 \\
\hline 35 & 99.6 & .008119 & 2.31 & 1.75 \\
\hline 40 & 105 & .008388 & 2.21 & 2.37 \\
\hline 45 & 108 & .008766 & 2.11 & 3.09 \\
\hline 50 & 110 & .009268 & 2.04 & 3.87 \\
\hline 55 & 110 & .009902 & 1.98 & 4.72 \\
\hline 60 & 109 & .01067 & 1.94 & 5.58 \\
\hline 65 & 108 & .01157 & 1.92 & 6.45 \\
\hline 70 & 106 & .01259 & 1.91 & 7.30 \\
\hline 75 & 104 & .01374 & 1.91 & 8.12 \\
\hline 80 & 102 & .01500 & 1.91 & 8.91 \\
\hline 85 & 100 & .01635 & 1.93 & 9.65 \\
\hline 90 & 98.4 & .01781 & 1.95 & 10.34 \\
\hline 95 & 96.7 & .01934 & 1.97 & 10.97 \\
\hline 100 & 95.1 & .02096 & 1.99 & 11.56 \\
\hline 110 & 92.3 & .02438 & 2.05 & 12.59 \\
\hline 120 & 90.1 & .02803 & 2.10 & 13.43 \\
\hline 130 & 88.3 & .03185 & 2.16 & 14.10 \\
\hline 140 & 86.9 & .03581 & 2.22 & 14.63 \\
\hline 150 & 85.7 & .03988 & 2.28 & 15.02 \\
\hline 160 & 84.7 & .04404 & 2.33 & 15.31 \\
\hline 170 & 83.8 & .04827 & 2.38 & 15.50 \\
\hline 180 & 83.0 & .05258 & 2.42 & 15.62 \\
\hline 190 & 82.2 & .05694 & 2.46 & 15.67 \\
\hline 200 & 81.4 & .06137 & 2.50 & 15.66 \\
\hline 220 & 79.8 & .07042 & 2.56 & 15.50 \\
\hline 240 & 78.2 & .07978 & 2.60 & 15.18 \\
\hline 260 & 76.6 & .08952 & 2.64 & 14.72 \\
\hline 280 & 75.3 & .09971 & 2.68 & 14.14 \\
\hline
\end{tabular}

a high-temperature standard reference material [2], it would be desirable to make use of it at low temperatures as well. The following analysis is given to indicate how Armco iron may be useful at low temperatures.

The Lorenz ratio, $\rho \lambda / T$, computed from these measurements is much less variable from specimen to specimen at low temperatures than either $\rho$ or $\lambda$. This is expected for materials which are primarily electronic thermal conductors. Figure 8 illustrates the deviations of the Lorenz ratios for each specimen from the mean values. Since these deviations are not appreciably larger than the uncertainty in the computed Lorenz ratio, the Lorenz ratio is assumed to be essentially invariant from specimen to specimen. Thus, one can compute the thermal conductivity of a particular specimen of Armco iron from its electrical resistivity and the Lorenz ratios reported here. 

TABLE 8. Transport properties of Armco iron,
specimen $4 C$

\begin{tabular}{c|c|c|c|c}
\hline \hline $\begin{array}{c}\text { Temper- } \\
\text { ature }\end{array}$ & $\begin{array}{c}\text { Thermal } \\
\text { conductivity }\end{array}$ & $\begin{array}{c}\text { Electrical } \\
\text { resistivity }\end{array}$ & $\begin{array}{c}\text { Lorenz } \\
\text { ratio } \times 10^{8}\end{array}$ & $\begin{array}{c}\text { Thermo- } \\
\text { power }\end{array}$ \\
\hline$K$ & $W m^{-1} K^{-1}$ & $\mu \Omega m$ & $V^{2} / K^{2}$ & $\mu V / K$ \\
6 & 19.6 & 0.007675 & 2.51 & -0.07 \\
7 & 23.0 & .007664 & 2.52 & .07 \\
8 & 26.3 & .007673 & 2.52 & .11 \\
9 & 29.6 & .007685 & 2.53 & .11 \\
10 & 32.9 & .007694 & 2.53 & .11 \\
12 & 39.4 & .007702 & 2.53 & .13 \\
14 & 46.0 & .007706 & 2.53 & .19 \\
16 & 52.5 & .007715 & 2.53 & .28 \\
18 & 58.9 & .007730 & 2.53 & .39 \\
20 & 65.1 & .007752 & 2.52 & .50 \\
& & & & \\
25 & 79.1 & .007834 & 2.48 & .80 \\
30 & 90.5 & .007960 & 2.40 & 1.18 \\
35 & 98.9 & .008149 & 2.30 & 1.66 \\
40 & 105 & .008427 & 2.20 & 2.27 \\
45 & 108 & .008814 & 2.11 & 2.97 \\
& & & & \\
50 & 109 & .009324 & 2.04 & 3.74 \\
55 & 110 & .009965 & 1.98 & 4.58 \\
60 & 109 & .01074 & 1.95 & 5.44 \\
65 & 107 & .01164 & 1.92 & 6.30 \\
70 & 106 & .01267 & 1.91 & 7.15 \\
75 & 104 & .01382 & 1.91 & 7.98 \\
80 & 102 & .01507 & 1.92 & 8.77 \\
85 & 99.8 & .01643 & 1.93 & 9.51 \\
90 & 97.9 & .01789 & 1.95 & 10.20 \\
95 & 96.2 & .01942 & 1.97 & 10.85 \\
100 & 94.6 & .02104 & 1.99 & 11.44 \\
110 & 91.8 & .02446 & 2.04 & 12.47 \\
120 & 89.6 & .02811 & 2.10 & 13.31 \\
130 & 87.9 & .03193 & 2.16 & 13.99 \\
140 & 86.5 & .03589 & 2.22 & 14.51 \\
& & & & \\
150 & 85.4 & .03996 & 2.28 & 14.91 \\
160 & 84.5 & .04412 & 2.33 & 15.20 \\
170 & 83.8 & .04836 & 2.38 & 15.39 \\
180 & 83.1 & .05267 & 2.43 & 15.51 \\
190 & 82.4 & .05704 & 2.47 & 15.56 \\
& & & & \\
200 & 81.8 & .06146 & 2.51 & 15.55 \\
220 & 80.4 & .07052 & 2.58 & 15.39 \\
240 & 78.8 & .07986 & 2.62 & 15.07 \\
260 & 77.0 & .08957 & 2.65 & 14.62 \\
280 & 75.3 & .09973 & 2.68 & 14.05 \\
300 & 73.8 & .11040 & 2.71 & 13.36 \\
\hline & & & & \\
\hline
\end{tabular}

In order for the above procedure to be practical, one needs a relatively quick method of generating a $\rho$ versus $T$ curve for a particular specimen from relatively few measurements. Matthiessen's rule indicates that $\rho=\rho_{0}+\rho_{i}$, where $\rho_{0}$ is the residual resistivity of the specimen and $\rho_{i}$ is the intrinsic resistivity of the material. It is known that this rule is not satisfied exactly and that a correction term $\Delta\left(\rho_{0}, \rho_{i}\right)$ exists. However, if this correction term is sufficiently small one can construct a sufficiently accurate $\rho$ versus $T$ curve for a given specimen from $\rho_{i}$, assumed to be the same for all specimens, and the value of $\rho_{0}$ as measured for each specimen. To investigate this possibility, $\rho_{i}$ was computed for each of the three specimens using Matthiessen's rule. The relative deviations of the com-
TABLE 9. The Lorenz ratio and intrinsic electrical resistivity of Armco iron

(Average of the results from specimens 2C, 2C (after annealing), and 4C)

\begin{tabular}{|c|c|c|}
\hline Temperature & Lorenz ratio $\times 10^{8}$ & $\begin{array}{l}\text { Intrinsic electrical } \\
\text { resistivity }\end{array}$ \\
\hline $\begin{array}{r}K \\
4 \\
5 \\
6 \\
7 \\
8 \\
9 \\
10\end{array}$ & $\begin{array}{l}V^{2} / K^{2} \\
2.263 \\
2.455 \\
2.505 \\
2.523 \\
2.531 \\
2.533 \\
2.532\end{array}$ & $\begin{array}{c}\mu \Omega m \\
0.0000 \\
.0000 \\
.0000 \\
.0000 \\
.0000 \\
.0000 \\
.0000\end{array}$ \\
\hline $\begin{array}{l}12 \\
14 \\
16 \\
18 \\
20 \\
25\end{array}$ & $\begin{array}{l}2.529 \\
2.528 \\
2.528 \\
2.527 \\
2.521 \\
2.477\end{array}$ & $\begin{array}{l}.0000 \\
.0000 \\
.0000 \\
.0001 \\
.0001 \\
.0002\end{array}$ \\
\hline $\begin{array}{l}30 \\
35 \\
40 \\
45 \\
50\end{array}$ & $\begin{array}{l}2.395 \\
2.292 \\
2.188 \\
2.096 \\
2.021\end{array}$ & $\begin{array}{l}.0003 \\
.0005 \\
.0008 \\
.0011 \\
.0016\end{array}$ \\
\hline $\begin{array}{l}55 \\
60 \\
65 \\
70 \\
75 \\
80\end{array}$ & $\begin{array}{l}1.965 \\
1.927 \\
1.905 \\
1.895 \\
1.895 \\
1.903\end{array}$ & $\begin{array}{l}.0023 \\
.0030 \\
.0040 \\
.0050 \\
.0061 \\
.0074\end{array}$ \\
\hline $\begin{array}{r}85 \\
90 \\
95 \\
100\end{array}$ & $\begin{array}{l}1.917 \\
1.935 \\
1.956 \\
1.980\end{array}$ & $\begin{array}{l}.0087 \\
.0102 \\
.0117 \\
.0134\end{array}$ \\
\hline $\begin{array}{l}110 \\
120 \\
130 \\
140 \\
150\end{array}$ & $\begin{array}{l}2.034 \\
2.091 \\
2.150 \\
2.209 \\
2.266\end{array}$ & $\begin{array}{l}.0168 \\
.0204 \\
.0242 \\
.0282 \\
.0323\end{array}$ \\
\hline $\begin{array}{l}160 \\
170 \\
180 \\
190 \\
200\end{array}$ & $\begin{array}{l}2.320 \\
2.371 \\
2.418 \\
2.461 \\
2.499\end{array}$ & $\begin{array}{l}.0364 \\
.0407 \\
.0450 \\
.0494 \\
.0538\end{array}$ \\
\hline $\begin{array}{l}220 \\
240 \\
260 \\
280 \\
300\end{array}$ & $\begin{array}{l}2.562 \\
2.610 \\
2.647 \\
2.682 \\
2.724\end{array}$ & $\begin{array}{l}.0628 \\
.0722 \\
.0819 \\
.0921 \\
.1028\end{array}$ \\
\hline
\end{tabular}

puted values of $\rho_{i}$ from the mean of three sets is shown in figure 9. This plot shows that $\rho_{i}$ values for these three specimens, as computed from Matthiessen's rule, differ from the mean by less than 0.3 percent of the total resistivity. This deviation is only slightly larger than the estimated uncertainty of the measurements. It is not unreasonable to assume that $\rho_{i}$ for other specimens is within a few tenths of a percent of the mean values of these three specimens. Thus, characterized Armco iron specimens may be used as low-temperature standards. The thermal conductivity, 


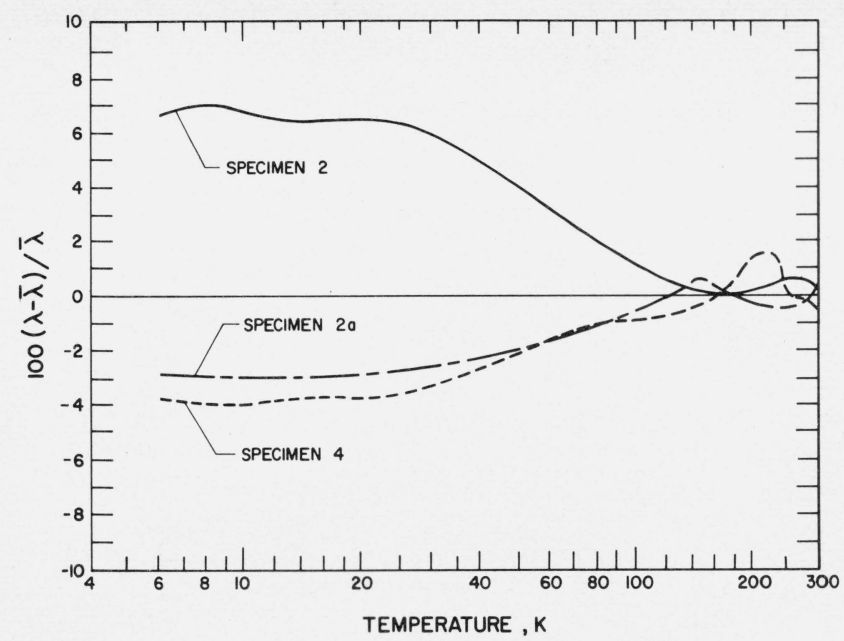

FIGURE 7. Deviations of the thermal conductivities of each specimen from the mean values.

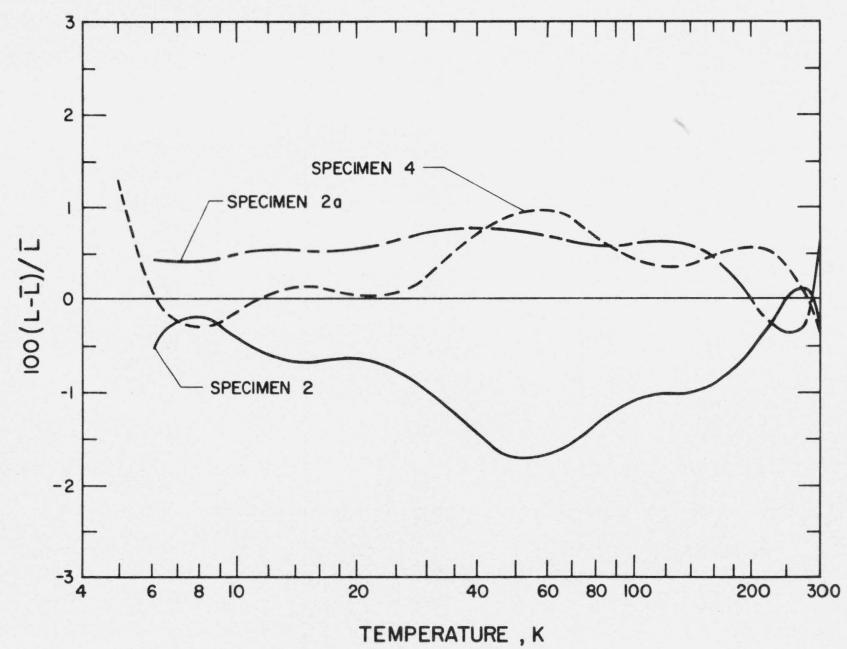

FIGURE 8. Deviations of the Lorenz ratios of each specimen from the mean values.

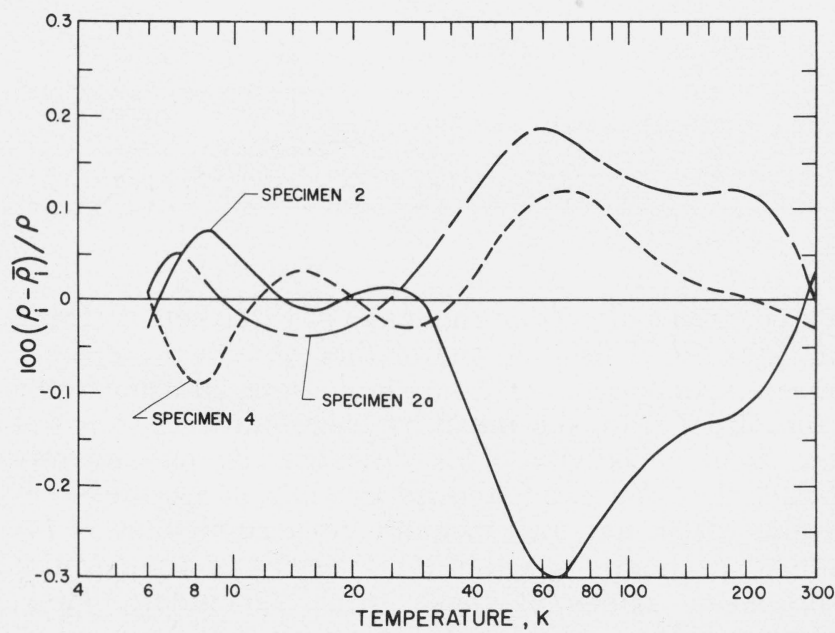

Figure 9. Deviations of the computed intrinsic electrical resistivities of each specimen from the mean values. $\lambda$, of a standard reference specimen of Armco iron according to these results may be computed from

$$
\lambda=\frac{L T}{\rho}=\frac{L T}{\rho_{i}+\rho_{0}}
$$

where $L$ and $\rho_{i}$ are given in table 9 and $\rho_{0}$ is determined by a relatively simple measurement.

Numerous thermal conductivity and electrical resistivity measurements on Armco iron have been reported; some of these measurements extend to temperatures as low as $-200^{\circ} \mathrm{C}$. R. W. Powell [2] reviewed the data published prior to 1962; this review indicates that the only low-temperature data at that time were those of Lucks and Deem [24]. Since that time low-temperature data have been reported by Fulkerson et al. [15]. Larsen et al. [25], R. W. Powell et al. [18], Shanks et al. [19], and Watson et al. [20]. These and other high-temperature measurements have been done as a result of a proposal by C. F. Lucks (Battelle Memorial Institute) to carry out a round-robin experiment on Armco iron. Reported data on these specimens can be interpreted to show (1) experimental differences between laboratories (assuming insignificant material variability), (2) material variability in a given lot of Armco iron (assuming insignificant experimental errors), or (3) a combination of (1) and (2) of comparable proportions. Not surprisingly, the latter seems to be the result of these measurements, as is indicated in the following discussion.

The electrical resistivity measurements are generally reported to be accurate to better than 1 percent. Thermal conductivity data are generally reported to be accurate to better than 3 percent. Thus, the uncertainty in Lorenz ratios caused by experimental measurement errors is expected to be less than 4 percent. The icepoint electrical resistivities measured by several investigators $[15,16,18,19,20,25]$ range from $0.09 \mu \Omega \mathrm{m}$ to $0.104 \mu \Omega \mathrm{m}$; this range $(14 \mathrm{n} \Omega \mathrm{m})$ is significantly larger than the expected uncertainty of the measurements. This is a larger material variation than we would expect on the following basis: Matthiessen's rule is expected to be reasonably correct, as confirmed by our measurements; and, thus, the same absolute variation observed in electrical resistivity at the ice point should also be observed in the residual resistivity. However the measured residual resistivities ranged only from 6.1 to $10.6 \mathrm{n} \Omega \mathrm{m}$ (a range of $4.5 \mathrm{n} \Omega \mathrm{m}$ ).

Some investigators $[15,19,20]$ have measured the electrical resistivity of several specimens to investigate the effect of heat treatment; their results show possible differences of several percent but it seems unlikely that at room temperature the real material differences exceed about 5 percent.

Since the electronic component of thermal conductivity is the major conductivity component in Armco iron, the specimen-to-specimen variation in electrical resistivity must be reflected in the thermal conductivity. However, since the experimental measurement uncertainty is not significantly smaller than the probable material variability, it is difficult to determine material differences. The variation in reported thermal 
conductivities from all sources near the ice point is about 6 percent, not unreasonable according to the previous comments.

As indicated previously, the Lorenz ratio should be more invariant from specimen to specimen than either electrical resistivity or thermal conductivity. Comparison of all the reported Lorenz ratios at $0{ }^{\circ} \mathrm{C}$ shows a variation of about 2.5 percent. Considering the previously estimated uncertainty of 4 percent, this is considered excellent agreement. However, it would appear that this agreement is fortuitous. Upon careful examination of the methods used by the various investigators, it is noted that the electrical resistivity and thermal conductivity measurements were performed either on different specimens or at different times. In the latter case the specimen was invariably either machined or heat treated between the two types of measurements. Since we know that specimen-tospecimen variations exist and, since we know that mechanical strain or heat treatment changes the transport properties, it follows that the Lorenz ratio should be calculated from nearly simultaneous measurements of electrical resistivity and thermal conductivity on the same specimen. This apparent operational discrepancy may explain the larger Lorenz ratio variation at low temperatures. For example, at -150 and $-200^{\circ} \mathrm{C}$ the differences between the extreme values of Lorenz ratio are about 12 percent. As pointed out previously, the specimen-to-specimen percentage variation in electrical resistivity and thermal conductivity is greater at low temperatures.

Although our purpose is primarily investigation at low temperatures, it seems that a comment regarding the use of Armco iron as a high-temperature reference material is in order. It is clear that variations from specimen to specimen and variations caused by heat treatment are several percent. Under these circumstances it is prudent to make "in place" calibrations by electrical resistivity measurements whenever Armco iron is used at high temperatures. At low temperatures it is probably sufficient to make a residual resistivity measurement for calibration purposes as previously described.

In conclusion, it appears that the available data neither confirm nor contradict our previous estimate of the invariance of the Lorenz ratio and the intrinsic electrical resistivity. However, since the specimens we used had a rather limited range of residual resistivity (6.7 to $7.6 \mathrm{n} \Omega \mathrm{m}$ ) compared to the high value observed by Fulkerson et al. [15] $(10.0 \mathrm{n} \Omega \mathrm{m})$, it would be desirable to make additional thermal and electrical measurements on a specimen having a higher residual resistivity.

The absolute thermopowers of these three specimens are compared in figure 10. The deviations between specimens are only slightly larger than the uncertainty in the tabulated values; thus no significant difference between specimens can be detected from this property. The thermopower values tabulated are absolute values although our measurements were carried out with respect to normal silver wire. The absolute thermopowers of normal silver reported by Borelius

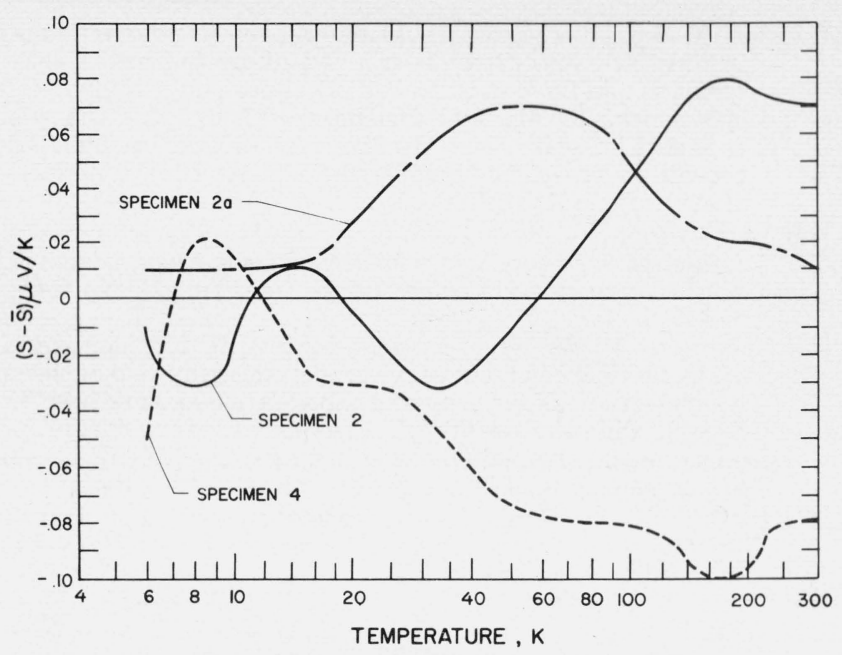

FIGURE 10. Deviations of the thermopowers of three specimens from the mean values.

et al. [26] were used to convert the experimental data to the absolute scale.

We wish to thank C. F. Lucks of Battelle Memorial Institute for supplying the Armco iron rod and information regarding annealing. R. P. Reed and R. L. Durcholz of this laboratory did the hardness and grain size testing.

\section{References}

[1] Hust, J. G., and R. L. Powell, Thermal conductivity of aerospace alloys at cryogenic temperatures, Proc. Eight Conf. Thermal Conductivity (eds. C. Y. Ho and R. E. Taylor, Plenum Press, New York, N.Y., 1969), pp. 197-208.

[2] Powell, R. W., Armco iron as a thermal conductivity standard, Review of published data, Progress in International Research on Thermodynamics and Transport Properties (eds. J. F. Masi and D. H. Tsai, Academic Press, New York, N.Y., 1962), pp. 454-465.

[3] Powell, R. L., Rogers, W. M., and Coffin, D. O., An apparatus for measurement of thermal conductivity of solids at low Temperatures, J. Res. Nat. Bur. Stand. (U.S.) 59, 349-355 (1957).

[4] Sparks, L. L., Powell, R. L., and Hall, W. J., Progress on cryogenic thermocouples, Advances in Cryogenic Engineering (ed. K. D. Timmerhaus, Plenum Press, New York, N.Y., 1969), Vol. 14, pp. 316-321. (Also to be published in more detail as an NBS Monograph.)

[5] Cataland, G., Edlow, M. H., and Plumb, H. H., Liquid helium vapor pressure regulator, Rev. Sci. Instr. 32, No. 8, 980-981 (1961).

[6] Hust, J. G., Thermal anchoring of wires in cryogenic apparatus, Rev. Sci. Instr. 41, 622-624 (1970).

[7] Hust, J. G., A compilation and historical review of temperature scale differences, Cryogenics 9, 443-455 (1969).

[8] Brickwedde, F. G., Durieux, M., Clement, J. R., and Logan, J. K., The $1958 \mathrm{He}^{4}$ scale of temperature, J. Res. Nat. Bur. Stand (U.S.), 64A (Phys. and Chem.), No. 1, 1-17 (1960).

[9] Eisenhart, C., Realistic evaluation of the precision and accuracy of instrument calibration systems, J. Res. Nat. Bur. Stand. (U.S.), 67C (Eng. and Instr.), No. 2, 161-187 (1963).

[10] Natrella, M. G., Experimental Statistics, Nat. Bur. Stand (U.S.), Handb. 91, (U.S. Government Printing Office, Washington, D.C., 1963).

[11] ASTM (1961), Use of the Terms Precision and Accuracy as Applied to Measurement of a Property of a Material, ASTM Designation E177-61T, ASTM Standards, Pt. 11, pp. 17581766. 
[12] $\mathrm{Ku}, \mathrm{H}$. H., Notes on the use of propagation of error formulas, J. Res. Nat. Bur. Stand. (U.S.), 70C (Eng. and Instr.), No. 4 (1966).

[13] Christiansen, R. M., and Hollingsworth, Jr., M., The performance of glass fiber insulation under high vacuum, Advances in Cryogenic Engineering (ed. K. D. Timmerhaus, Plenum Press, New York, N.Y., 1960), Vol. 4, p. 141.

[14] Christiansen, R. M., and Marsh, H. N., Jr., Low temperature insulating systems, Advances in Cryogenic Engineering (ed. K. D. Timmerhaus, Plenum Press, New York, N.Y., 1960), Vol. 5, p. 171.

[15] Fulkerson, W., Moore, J. P., and McElroy, D. L., Comparison of the thermal conductivity, electrical resistivity, and Seebeck coefficient of a high-purity iron and an Armco iron to $1000{ }^{\circ} \mathrm{C}$, J. Appl. Phys. 37, 2639-2653 (1966).

[16] Laubitz, M. J., Thermal and electrical properties of Armco iron at high temperatures, Can. J. Phys. 38, 887-907 (1960).

[17] Laubitz, M. J., The unmatched guard method of measuring thermal conductivity at high temperatures, Can. J. Phys. 41, 1663-1678 (1963)

[18] Powell, R. W., Hickman, M. J., Tye, R. P., and Woodman, M. J., Armco iron as a thermal conductivity standard; New determinations at the National Physical Laboratory, Progress in International Research on Thermodynamics and Transport
Properties, (ASME, Academic Press, New York, N.Y., 1962), pp. $466-473$.

[19] Shanks, H. R., Klein, A. H., and Danielson, G. C., Thermal properties of Armco iron, J. Appl. Phys. 38, 2885-2892 (1967).

[20] Watson, T. W., Flynn, D. R., and Robinson, H. E., Thermal conductivity and electrical resistivity of Armco iron, J. Res. Nat. Bur. Stand. (U.S.), 71C (Eng. and Instr.) 285-291 (1967).

[21] Lucks, C. F., Private communication.

[22] Bjorck, A., Solving linear least squares problems by GramSchmidt orthogonalization, BIT 7, 1-21 (1967).

[23] Golden, J. T., FORTRAN IV - Programming and Computing (Prentice-Hall, Inc., Englewood Cliffs, N.J., 1965).

[24] Lucks, C. F., and Deem, H. W., Thermal properties of thirteen metals, ASME Spec. Tech. Publ. No. 227 (Feb. 1958).

[25] Larsen, D. C., Powell, R. W., and Dewitt, D. P., The thermal conductivity and electrical resistivity of a round-robin Armco iron sample, initial measurements from 50 to $300^{\circ} \mathrm{C}$, Proc. Eighth Thermal Conductivity Conf. (eds. C. Y. Ho and R. E. Taylor, TPRC, Plenum Press, N.Y., 1969), pp. 675-686.

[26] Borelius, G., Keesom, W. H., Johansson, C. H., and Linde, J. O., Establishment of an Absolute Scale for the Thermoelectric Force, Proc. Kon. Akad. Amsterdam 35, 10 (1932).

(Paper 74A5-632) 